This is the final peer-reviewed accepted manuscript of:

Arduini, T., lorio, D., \& Patacchini, E. (2019). Weight, reference points, and the onset of eating disorders. Journal of health economics, 65, 170-188.

The final published version is available online at:

https://doi.org/10.1016/j.jhealeco.2019.03.004

Rights / License:

The terms and conditions for the reuse of this version of the manuscript are specified in the publishing policy. For all terms of use and more information see the publisher's website.

This item was downloaded from IRIS Università di Bologna (https://cris.unibo.it/)

When citing, please refer to the published version. 


\title{
Weight, Reference Points, and the Onset of Eating Disorders*
}

\author{
Tiziano Arduini ${ }^{\dagger} \quad$ Daniela Iorio Eleonora Patacchini $^{\ddagger}$
}

February 11, 2019

\begin{abstract}
We investigate whether the development of eating disorders, in the form of purging, is influenced by peers' body size through interpersonal comparisons. Using detailed information on recent cohorts of U.S. teenagers, we document a sizeable and significant negative effect of high school peers' body mass index (BMI) on purging behavior during the adolescence for females, but not for males. Interpersonal comparisons operate through the formation of a distorted self-perception: teenage girls with relatively thin female peers perceive themselves as heavier than they actually are. The girls who are more susceptible to peer influences are those having peers who are thinner, more popular, more (verbally) able, and with more educated parents.
\end{abstract}

Keywords: Peer Effects, Relative BMI, Health Behavior.

JEL classification: I12

${ }^{*}$ We thank the editor and two anonymous reviewers for very helpful comments on an earlier draft of this paper. We thank Michelle Sovinsky and seminar participants at the University of Bologna, Cergy-Pontoise, EEA summer meetings, and IX IBEO-Health Economic Workshop for useful conversations and comments.

${ }^{\dagger}$ University of Bologna. E-mail: tiziano.arduini@unibo.it.

${ }^{\ddagger}$ University of Bologna. E-mail: daniela.iorio@unibo.it.

${ }^{\S}$ Corresponding author. Cornell University, EIEF, CEPR and IZA. E-mail: ep454@cornell.edu. 


\section{Introduction}

According to the National Eating Disorders Association, approximately 20 million women in the United States struggle with an eating disorder (ED) at some time in their life, including anorexia nervosa, bulimia nervosa, binge eating and purging disorders. EDs are potentially life-threatening conditions that affect a person's emotional and physical health in a severe way. EDs may have detrimental effects on cognitive development in children, impair concentration and focus in adolescents, and lead to lower productivity and days lost from work among adults. The seriousness of clinically significant EDs is also exacerbated by the fact that EDs remain challenging to diagnose and treat because patients may be hesitant to seek treatment and tend to persist in their behaviors (Keel et al., 2005; Ham et al., 2013). Their health worsens as EDs develop into more severe stages. In the United States, EDs is the third most common form of chronic illness in the adolescent female population (American Psychiatric Association, 2013).

Despite the severity of EDs, they have only recently received the attention of policy makers. In December 2016, the US Congress passed the first piece of federal legislation specifically designed to help people with EDs in the form of more accessible treatment and prevention across the nation. At the state level, in 2013 Virginia was one of the first States to pass a law requiring provision of ED education and a voluntary ED screening program for students. While there is an increasing effort to design and provide educational and prevention interventions, little is known about their effectiveness at reducing the onset of ED cases (Chao et al., 2014). However, understanding the drivers of EDs at the onset age is crucial because earlier treatment increases the likelihood of physical and emotional recovery.

In this paper, we draw insights from the psychology literature on peers' influence during adolescence to study a specific channel that might be relevant in the development of EDs. In particular, we consider whether purging is influenced by peers' average body size through interpersonal comparisons. ${ }^{1}$ Adolescents are strongly attuned to how they are perceived by those around them, and peers play a substantial role in defining social expectations,

\footnotetext{
${ }^{1}$ We consider the body size of the peers rather than their actual behavior since EDs are secretive behaviors, which are closely associated with shame and self-loathing (Wilson et al., 1993; Fairburn and Cooper, 1982; Cooper and Fairburn, 1987, among others).
} 
establishing identity, and evaluating oneself (Brown et al., 1994). Body image constitutes a major aspect of self-representation and self-evaluation during adolescence and peers provide comparison targets along this dimension. As a result, negative self-evaluations contribute to body dissatisfaction, which in turn may drive the development of EDs (Arigo et al., 2014). ${ }^{2}$

In our analysis, we consider schoolmates in the same grade as reference points. We define the reference group in this way because of the large literature in social psychology arguing that the school environment and its students are important determinants of adolescents' selfconcept. Indeed, adolescents spend a large fraction of their time at school, where they are constantly confronted with peers who provide comparison information about grades, physical appearance, and sports performance (Dijkstra et al., 2008; Buunk and Gibbons, 2007; Keel et al., 2005; Jones et al., 2004).

Quantitatively assessing the importance of this reference group embeds all the common challenges in the estimation of peer effects. We address these challenges by using quasirandom variation in exposure to fellow students within schools and across grades. The idea is to treat the composition of students by grade within a school as quasi-random and use this quasi-random variation as opposed to the variation that can be traced to parental school and residential decisions. This approach has been widely used in studying peer effects in various contexts (e.g. Hoxby, 2000; Hanushek et al., 2003; Angrist and Lang, 2004; Friesen and Krauth, 2007; Bifulco et al., 2011; Lavy and Schlosser, 2011; Lavy et al., 2012; Patacchini and Zenou, 2016; Olivetti et al., 2018).

To implement this approach we use data from the National Longitudinal Survey of Adolescent Health (Add Health). This survey collects information about BMI, body perception, and unhealthy weight control behaviors (UWCB), such as purging, for recent cohorts of U.S. teenagers and their schoolmates. We focus on the likelihood of purging during adolescence because UWCB are risk-factors for full syndrome EDs (Steinhausen et al., 2005). As documented by American Psychiatric Association (2013), purging is observed both in anorexia nervosa and bulimia nervosa.

Our results reveal that interpersonal comparisons contribute to the onset of EDs for

\footnotetext{
${ }^{2}$ See Leahey et al. (2011) and Myers and Crowther (2009) for an exhaustive review of the psychological literature on social comparisons and body dissatisfaction, and Stice and Shaw (2002) for a review of the psychological literature on the importance of social comparisons in shaping body satisfaction.
} 
females, but not for males. In addition, not all fellow students have the same influence: only females peers appear to be used for comparison. The effect of the average BMI in the reference group on the probability of purging is significant, sizeable, and negative. A 5 percent increase of group BMI, which is about 1 standard deviation, is associated with a decrease in the probability of purging of about 1 percentage point one year later. Such an effect is rather large when we consider that the prevalence of purging in our sample is 2.5 percent. Relatively heavy girls (i.e. those with a BMI more than one standard deviation above average) are the most susceptible to peer influence. The estimated effect of peers' BMI for these girls is almost 6 times larger than the one obtained for girls with a BMI around the mean of the peer group. We also find that the estimated effect of peers' BMI is significantly larger for less popular girls (i.e. those with a number of friends at least one standard deviation below the average), those with lower (verbal) ability, and those with less educated parents.

In addition to estimating the importance of interpersonal comparisons in body size for the onset of EDs, we investigate the pathway responsible for this effect. Results reveal that females with thinner peers perceive themselves heavier than they actually are, and this distorted perception acts as a mediator for the relationship between group BMI and purging.

The idea that individuals assess themselves relative to others has long been recognized in sociology and psychology (Festinger, 1954; Miller et al., 1988; Lockwood and Kunda, 1997). However, it is only recently that the economics literature has provided evidence on the importance of social image concerns for a wide range of behaviors, such as education, consumption, investment decisions, effort in the workplace, voting and charitable giving (Mas, 2006; Fehr and Goette, 2007; Farber, 2008; Card et al., 2012; Charité et al., 2015; Exley and Terry, 2017; Bursztyn and Jensen, 2017). Our analysis contributes to this literature by providing empirical results about how and why interpersonal comparisons affects healthrelated behavior during adolescence.

Our findings are consistent with a variety of different theories in economics about the importance of social comparisons in shaping individual behavior (see, e.g. Akerlof and Kranton, 2000; Battaglini et al., 2005, 2017; Patacchini and Zenou, 2012; Patacchini and Venanzoni, 2014; Liu et al., 2014). They are also in line with the cross-country evidence documented 
by Blanchflower et al. (2009). Using Eurobarometer data on 29 European countries, they show that own body dissatisfaction, overweight perceptions, and dieting decisions correlate with own BMI relative to the national average for the same gender and age group. Using the same data, Costa-Font and Jofre-Bonet (2013) reach similar conclusions. In the latter case, the outcome of interest is a distorted body perception (as the respondent claims to be "just fine" or "too fat") when, instead, the respondent's BMI is below 17.5, which might be indicative of anorexic behaviors. ${ }^{3}$

Our evidence suggests that community programs promoting body acceptance and ways to buffer the potentially negative effects of social comparisons are indeed a promising avenue to tackle EDs challenges for female adolescents.

The remainder of the paper is organized as follows. Section 2 discusses the data and some preliminary evidence. Section 3 describes the identification strategy. Section 4 presents our main estimates of the effects of group BMI for the onset of EDs. Section 5 explores the roots of social comparison. Robustness exercises are discussed in Section 6. Section 7 concludes.

\section{Data}

The National Longitudinal Survey of Adolescent Health (Add Health) is a longitudinal data set that examines health-related behaviors of adolescents who were in grades 7 through 12 in the 1994-1995 school year. It is a school-based, stratified, random sample of middle and high schools in the United States. ${ }^{4}$ Every student attending the sampled schools on the interview day was asked to complete a questionnaire (in-school data) containing questions on respondents' demographic and basic family background characteristics. A subset of students selected from the rosters of the sampled schools - about 20,000 individuals - was then asked

\footnotetext{
${ }^{3}$ Our paper is also related to the studies examining peer effects in body weight (see, Yakusheva et al., 2014; Fortin and Yazbeck, 2015; Dieye and Fortin, 2017, for recent contributions), and to the wide literature looking at peer effects in obesity. See Balsa and Díaz (2018) for a recent review of this literature and Cawley (2015) for a review of the economic causes and consequences of obesity.

${ }^{4}$ The Add Health is a program project directed by Kathleen Mullan Harris and designed by J. Richard Udry, Peter S. Bearman, and Kathleen Mullan Harris at the University of North Carolina at Chapel Hill, and funded by grant P01-HD31921 from the Eunice Kennedy Shriver National Institute of Child Health and Human Development, with cooperative funding from 23 other federal agencies and foundations. Information on how to obtain the Add Health data files is available on the Add Health website (http://www.cpc.unc.edu/addhealth). No direct support was received from grant P01-HD31921 for this analysis.
} 
to complete a longer questionnaire containing more sensitive individual and household information (in-home and parental data). Those subjects were interviewed again in 1995-1996 (Wave II), in 2001-2002 (Wave III), and in 2007-2008 (Wave IV).

The in-home questionnaire includes detailed questions about weight, height, and unhealthy weight control behavior. We use this information to construct our outcome variable. The fifth edition of the Diagnostic and Statistical Manual of Mental Disorders (DSM-5) lists purging under the "Other Specified Feeding or Eating Disorder" (henceforth, OSFED) category. Methods of purging include forced vomiting, excessive use of laxatives or diuretics, and extreme or prolonged periods of exercising. Based on this definition, we construct an indicator of purging behavior from the Add Health data using the answers to the question "During the past seven days, which of the following things did you do in order to lose weight or to keep from gaining weight: vomit, laxatives, diet pills, exercise". The index takes the value 1 if the respondent engages in at least one form of these unhealthy weight control behaviors (excluding exercise) and 0 otherwise. ${ }^{5}$

The Add Health data reports the BMI of each respondent. It is calculated using selfreported height and weight from the in-home data. To investigate the presence of measurement error in these assessments, we compare the distribution of the BMI of the students in the Add Health with the one obtained using the National Health and Nutrition Examination survey (NHANES). ${ }^{6}$ We pull the data from the survey year 1999-2000, as it is the closest time span to the Add Health Waves I and II. We consider the BMI of adolescents in the same age (between 14 and 17), gender, and race groups, and we plot the two distributions in Figure 1. They appear remarkably similar. We formally test the hypothesis that the distance between the empirical distributions of the two samples is zero using a Mann-Whitney two-sample statistic. We fail to reject the null hypothesis that the two samples are drawn independently from the same distribution (p-value equal to 0.39).

Our main variable of interest is the BMI in the reference group (group BMI hereafter).

\footnotetext{
${ }^{5}$ We exclude exercising because, based on the available information, we cannot detect its excessive and prolonged forms.

${ }^{6}$ This survey is provided by the National Center for Health Statistics, Division of Health Examination Statistics, as part of the Centers for Disease Control and Prevention. Every year, approximately 5,000 individuals complete the health examination component of the survey. A majority of the health examinations are conducted in mobile examination centers, which provide an ideal setting for the collection of high quality data in a standardized environment.
} 
We consider schoolmates in the same grade as reference points. Group BMI is the mean BMI of the leave-one-out distribution of students belonging to a specific grade and school. That is, for each student $i$, this variable is the average BMI of peers after eliminating student $i$ from the distribution. While the information on school mates and the individual BMI is from Wave I, the indicator of purging behavior is from Wave II. This is done to mitigate reverse causality issues. We discuss these issues in more detail in Section 4.

The information on students demographic characteristics and family background is taken from the in-school, in-home and parental questionnaires in Wave I. In the parental questionnaire, the student's resident mother is asked to participate in a 40-minute intervieweradministered survey. ${ }^{7}$ Using this questionnaire, we construct the variable "parental obesity" that takes the value 1 if the respondent reports that the child's biological mother or the child's biological father is obese. From the Wave I parental questionnaire we also construct an indicator of the social structure of families and extract information on family income. ${ }^{8}$ From the in-home data we pull information about birth order from the household roster, and the student's scores for an abbreviated version of the Peabody Picture Vocabulary Test (PVT), which is administered at the beginning of the survey. The PVT is an abbreviated version of the full-length Peabody Picture Vocabulary Test (PPVT), a test used to assess verbal abilities and receptive vocabulary. ${ }^{9}$ The follow-up interviews of the in-home surveys contain rich information about mental health, health and lifestyle habits, and perception of body image, which enable us to inspect the pathway for our results. We will detail these variables in Sections 5 and 6. Parental education is instead recorded in the in-home data. ${ }^{10}$

\footnotetext{
${ }^{7}$ If the student's resident mother is unavailable, they interviewed another adult in the household. Overall, 93 percent of parent interviews took place with a female parent.

${ }^{8}$ Specifically, the variable "Married parents" takes the value 1 if the resident parent who answers the questionnaire reports being married, and 0 otherwise. We pull information on family income using the declared total income from any sources before taxes. If family income is missing, we imputed the family income as the mean of the sample conditional on gender, race, and parental education, and include a dummy for missing family income.

${ }^{9}$ Scores are standardized by age to a mean of 100 and standard deviation of 15 for each age group, and neither the student nor the interviewer is made aware of the results of the test.

${ }^{10}$ Students are asked, for each parent, to select how far each of their biological parents went in their education, with possible answers: "never went to school", "not graduate from high school", "high school graduate", "graduated from college or a university", "professional training beyond a four-year college". If the information is available for both residential parent, we select the highest level of education. We construct a variable "Less than college", which is coded as 1 if the parent is "not graduate from high school" or "high school graduate", and a variable "College+", which is coded as 1 if the parent is "graduated from college or a university" or "professional training beyond a four-year college". The base category is "never went to
} 
Our analysis focuses on students in grades 10-12, because it is in this age range that adolescents are more prone to social comparison (see for example Jones, 2001). We are able to follow about 5,000 students (3,068 girls and 1,929 boys) in grades 10-12 from Wave I to Wave II. We exclude students with missing values in our target and control variables and students who have fewer than 10 schoolmates in their grade (corresponding to the 5th percentile of the cohort-size distribution in our sample). ${ }^{11}$ Our final sample consists of 3,535 students, 2,178 girls and 1,357 boys. ${ }^{12}$

Table 1 reports the descriptive statistics of ED related outcomes and other individual characteristics for adolescents in our entire sample. Consistent with the epidemiological literature, boys and girls display statistically significant differences in the rates of purging, with a larger prevalence among girls. The probability of purging increases with age: the incidence is about 2.5 percent when girls are about 16 years old (in Wave II) and rises to 10 percent six years later (in Wave III). The prevalence of ED diagnosis, anorexia and/or bulimia nervosa (henceforth $\mathrm{AN} / \mathrm{BN}$ ) in Wave III is above 4 percent.

Girls make up about 60 percent of the sample. Around 70 percent of the sample is White, 20 percent is Black or African American, 10 percent is Hispanic/Latino and the reminder is Asian. Regarding student family background, about 72 percent of the adolescents in our sample have parents who are married, roughly 50 percent have parents who have at most completed high school, and 40 percent have parents who are college graduates or above. Finally, 25 percent of our adolescents have at least one parent who is obese.

According to the World Health Organization (WHO) classification, an individual is very underweight (henceforth $\mathrm{VUW}$ ) if $\mathrm{BMI}<16$; underweight (UW) if her BMI is in the range $[16,18.5]$, of normal weight $(\mathrm{NW})$ if her BMI is in the range $[18.5,25]$; overweight $(\mathrm{OW})$ if her BMI is in the range [25,30]; and obese (OB) if her BMI is above 30. Figure A.1 in the Appendix displays the distribution of individual BMI and group BMI for the adolescents in our sample. The pictures show that the distribution of student BMI is bell shaped, centered on 23 , which is close to the mid-point of the NW range, and right-skewed. The density of

school".

${ }^{11}$ We also exclude approximately 150 students who did not identify themselves as either White, Black or African American, Hispanic or Latino, or Asian.

${ }^{12}$ In Table A.1, we detail our sample selection procedure. Table A.1 shows that the composition of our sample is roughly unaffected by the selection process. 
group BMI is a more symmetric distribution centered again around 23. Figure A.2 displays the distribution of group BMI by reference group size. Cohort (reference group) size varies between 10 and 236 in our sample. The picture shows a relatively uniform distribution, indicating that the variation in group BMI is not the result of different cohort sizes.

In Figure 2, we plot the predicted probabilities of purging as a function of individual BMI and group BMI in panel (a) and (b), respectively. The probability of purging is increasing and convex in the individual BMI. The probability of purging is on average about 1 percent among UW students, and it increases to roughly 4 percent among OB students. Panels (b) and (c) reveal an interesting pattern. The probability of purging is decreasing in group BMI (panel (b)). Respondents are more likely to purge when they face a reference group of thin students than when they face a heavy reference group. Further, the frequency of purging is increasing and convex in the deviation of individual BMI from the average BMI of the schoolmates (panel (c)). ${ }^{13}$

\section{Empirical Model and Identification Strategy}

We begin our empirical investigation by providing evidence that purging behavior is an appropriate measure for the onset of EDs. The Wave III questionnaire (when individuals are on average 22 years old) asks whether the respondent has been diagnosed with Bulimia Nervosa (BN) or Anorexia Nervosa (AN). This follow-up information is used to document the EDs patterns from adolescence to young adulthood. We construct an indicator of ED diagnosis using the interviewer response to the question: "Have you ever been told by a doctor that you have ED such as anorexia nervosa or bulimia?". The index takes the value 1 for those answering yes to this question and 0 otherwise. We compute the probability of being diagnosed with AN/BN in early adulthood (in Wave III) conditional on purging behavior during adolescence (about 17 years old in Wave II). Specifically, the likelihood of being diagnosed with $\mathrm{AN} / \mathrm{BN}$ is 12.5 percent for young women who were purging in Wave II. This frequency decreases to 3.7 percent for those who did not purge in Wave II. As a result, purging appears as an important risk-factor for the development of EDs, as adolescents who

\footnotetext{
${ }^{13}$ The predicted probabilities are estimated using a logit regression.
} 
purge are 3 times more likely to develop AN/BN.

When we condition on individual characteristics and perform a regression analysis, we obtain similar results, though sample sizes are substantially reduced due to attrition in Wave III. Specifically, we regress the indicator on AN/BN diagnosis in early adulthood (Wave III) on the indicator of purging during adolescence controlling for race/ethnicity dummies, age, income, education level, and marital status. ${ }^{14}$ Results are shown in Table 2. Column (1) reports the results for the entire sample, whereas columns (2) and (3) split the results by gender. The estimates in column (1) indicate that young adults who were purging when adolescents are 3.5 times more likely of being to be diagnosed with AN/BN later on (given an estimate of 0.096 and a prevalence of $\mathrm{AN} / \mathrm{BN}$ of about 2.6 percent). This is in line with the considerations of epidemiologists that purging is a symptom of a number of EDs (Steinhausen et al., 2005). In fact, individuals who endorse any purging behavior are given a clinical referral, they are not just identified as high risk (Keel et al., 2005; Kass et al., 2017). Looking at gender differences in columns (1) and (2), one can see that the association between purging and ED diagnosis is driven by girls. The coefficient estimated on the boys subsample is close to zero and not significant (column (3)). In sum, the fact that teens' purging is highly correlated with EDs in adulthood provides salience for the study of the mechanisms through which those unhealthy weight-control habits are formed during adolescence.

We next turn to our main regression that investigates the relationship between purging behavior and group BMI. The Add Health data include students from multiple cohorts and are thus ideal for exploiting cross-cohort variation within a school to estimate the effect of schoolmates' characteristics on individual behavior. Our baseline regression model is:

$$
y_{i g s}=\alpha_{g}+\beta_{s}+x_{i s g}^{\prime} \gamma+\theta_{1} b m i_{i s g}+\theta_{2}, \overline{b m i}_{i s g}+\epsilon_{i g s}
$$

where $i$ denotes individuals, $g$ grades, and $s$ schools. $y_{i g s}$ is an indicator of purging behavior for a student $i$ in grade $g$ and school $s$ in Wave II (1996), $\alpha_{g}$ is a grade effect, $\beta_{s}$ is a school effect, $x_{i g s}$ is a vector of the student's characteristics, $b m i_{i s g}$ is the natural logarithm of body

\footnotetext{
${ }^{14}$ Information on education (measured in years), income (self-reported total personal income before taxes), and marital status (an indicator taking the value 1 if the respondent declares to be married, and 0 otherwise) is taken from Wave III.
} 
mass index of student $i$ in grade $g$ and school $s$ in Wave I (1995), $\overline{b m i}_{\text {isg }}$ denotes the natural logarithm of the average $b m i_{i s g}$ of students in grade $g$ and schools in Wave I. Finally, $\epsilon_{i g s}$ is the error term, and we allow for correlation within observations of the same school and grade. The use of lagged values of group BMI and individual BMI mitigates the reverse causality issue. In particular, reverse causality is present if purging in Wave II influences the individual BMI in Wave II. Note, though, that girls engaging in bulimic behavior (recurrent episodes of bingeing and purging) are subject to weight fluctuations but they are not systematically heavier than non-bulimic girls (Ham et al., 2013). We adopt a logarithmic transformation of the variables to account for a nonlinear relation between purging and BMI (as documented in Section 2).

We include controls for race/ethnicity and family background (including family income, parental education, and social structure of families) because these factors may be related to EDs and BMI. In addition, we control for Peabody Picture Vocabulary Test (PVT) score from Wave I, which may affect self-esteem that is typically highly correlated with body perception and satisfaction. In fact, verbal IQ and cognitive skills may serve as a moderating force against the development of body image concerns (Littleton and Ollendick, 2003). Another control is birth order as the general view is that the first born is likely to face higher risks of developing EDs, though the results of clinical studies are not conclusive (see e.g., Eagles et al., 2005; Goodman et al., 2014). Finally, we include an indicator for parental obesity, because parental obesity has been shown to be a risk factor for the development of BN through promotion of body dissatisfaction (Hill, 2007).

The grade and school fixed effects control for selection issues. The idea is to compare the outcomes of students who are in cohorts with heavier individuals with the ones of students in cohorts with thinner individuals. The identifying assumption is that this within-school across-grade variation is quasi-random. In particular, it is not correlated with observable or unobservable factors which are considered by parents when making school or residential decisions.

Our ability to exploit this identification strategy relies on the assumption that there is sufficient residual variation in our main variable after removing cohort and school fixed effects. Table 3, panels (a) and (b) shows that this is indeed the case. Removing fixed effects 
(from (a) to (b)) reduces the standard deviation in our target variable for both the girls and boys subsamples, but more that 60 percent of the variation remains.

Before turning to the estimation results, following Lavy and Schlosser (2011), we provide evidence on the validity of our identification strategy by checking whether cohort averages of students' BMI within a school are correlated with students' background characteristics such as parents age, family size, parental country of birth, marital status, race, parental education, and parental obesity. ${ }^{15}$ According to our identifying assumption, variation in group BMI should be unrelated to the variation in a number of predetermined characteristics of an individual student (after controlling for school and grade fixed effects). Table 4 provides these balance tests by reporting the estimated coefficients from within-school regressions of various student characteristics on the student's cohort average BMI. As shown in the table, almost none of the estimated correlations are significantly different from zero in the girls subsample. ${ }^{16}$ As Altonji et al. (2005) suggest, the degree of selection on observables can provide a good indication of the degree of selection on unobservables. In light of this argument, the evidence from Table 4 supports the assumption that our model specification identifies a source of variation that is unrelated to other student characteristics.

\section{Estimation Results}

The OLS estimation results of model (1) are reported in Table 5. Standard errors are clustered at the school-by-grade level. We begin with a basic model in column (1), which includes only the individual BMI, group BMI and gender. The point estimate of the effect of group BMI on purging is significant and negative: a 5 percent increase in group BMI (about one standard deviation) is associated with a decrease in the likelihood of purging of about 0.8 percentage points one year later. The size of the effect is quite large if we consider that the overall prevalence rate of purging in Wave II is 1.8 percent. In columns (2)-(4) we increase the set of individual characteristics as listed in model (1). We add ethnicity and PVT score in column (2), family background characteristics (family income, marital

\footnotetext{
15 "Parent age" and "Parent country of birth" are the age and country of birth of the parent who responds to the parental questionnaire, respectively.

${ }^{16}$ For boys, three estimated correlations are statistically different from zero (the race indicator for Hispanic or Latino, family income and parental education). Our analysis, however, will mainly focus on girls.
} 
status of parents, parental education, and number of siblings) in column (3), and finally an indicator of parental obesity in column (4). The results show that the estimated coefficient of group BMI is virtually identical across columns. Henceforth, our baseline specification is the model with the largest set of controls, grade fixed effects, and school fixed effects. ${ }^{17}$

Looking at the coefficients of the control variables, we find that girls are significantly more likely to engage in purging behavior than boys, in line with our descriptive evidence in Table 1. We also find that adolescents with married parents are less likely to purge than adolescents with single, never married, divorced, separated, and widowed parents. This is consistent with the psychological literature that identifies divorce and/or separation of parents as a potential risk factors for the development of EDs (see e.g., Hilbert et al., 2014). Further, Black or African-American and Asian teenagers are less likely to purge than Whites. This finding is in line with the evidence gathered by Crago et al. (1996), who review the epidemiological literature studying eating behaviors and disturbances among women and girls belonging to American minority groups. ${ }^{18}$ It also appears that family income and parental education do not predict purging behavior. While this evidence may be surprising in light of the historical perception that EDs are affecting predominantly White and rich women and girls (see e.g., Bruch et al., 1974) several studies in the epidemiological literature document conflicting evidence that ED symptoms are equally distributed across socio-economic status (see e.g., Mulders-Jones et al., 2017). ${ }^{19}$

In the last column of Table 5 we present the estimation results of our model when removing individual BMI. We perform this exercise to mitigate concerns about possible reverse causality affecting individual BMI, which would bias our estimates. The results

\footnotetext{
${ }^{17}$ We also run a regression of the baseline specification including school-specific linear time trends. The estimated group BMI coefficient remains almost unchanged (point estimate goes from 0.167 to 0.178).

${ }^{18}$ The bulk of this literature shows that restrictive dieting and self-induced vomiting are less frequent among Black and Asian American females than among Caucasian females. In particular, even though Black women and girls tend to be heavier and exercise less than their Caucasian counterparts, they experience less body dissatisfaction and weight concerns. More recently, using data from the 2001-2003 National Survey of American Life, Taylor et al. (2007) find that binge eating, without purging, is the most prevalent ED among the Black population in the US.

${ }^{19}$ The stereotype that EDs are affecting predominantly the White and rich population in the US has been nourished by the significant ethnic disparities in health care access for EDs and diagnosis. Cultural differences in seeking treatment and symptom presentation, as well as referral patters contribute to these differences. In particular, ethnic minorities are less likely than Whites to receive a clinician's recommendation for further evaluation or care (Becker et al., 2003; Marques et al., 2011).
} 
are reassuring: the magnitude of the estimated effect of group BMI in this last column is remarkably similar to the ones in the other columns.

We continue our analysis by exploring alternative definitions of reference points. The prevalent paradigm in the psychological literature is that there are gender differences in the effects of social comparisons, and that same-gender peers are the targets of social comparisons for physical attributes (see, e.g. Jones, 2001). We test this theory in Table 6. Column (1) reports the estimation results of our model for girls and Column (2) for boys. In both cases, we consider same-gender peers as reference points. In columns (3) and (4) we instead consider opposite-gender peers as reference points, for girls and boys respectively. The estimated coefficients for group BMI in columns (1) and (2) suggest that while girls are negatively affected by their peers, males are not. Furthermore, the estimated effect of group BMI is statistically significant only when same-grade female schoolmates serve as basis for comparison (column (1) versus column (3)). This finding provides empirical support for the theory mentioned above. For girls, the estimated coefficient is -0.20 , which implies that a 5 percent increase in group BMI (about one standard deviation) is associated with a decrease in the probability of purging of about 1 percentage point one year later. The magnitude of the estimated effect is rather large if we consider that the probability of purging is 2.5 percent in the girls subsample.

It is interesting to note that the estimated semi-elasticity of group BMI (in absolute value) is about 3.5 times larger than that one of individual BMI. Given that the standard deviation of individual BMI is 3 times larger than the standard deviation of group BMI, the two coefficients are of similar size in absolute value. We formally test for the equality of the effects in absolute value, i.e. $\theta_{1}=-\theta_{2}$, and find that indeed we cannot reject the null hypothesis. We will return to this finding when inspecting the mechanism in Section 5 . In the case of boys, we see no effect of group BMI on purging behavior regardless of the gender of the target group. The effects of the control variables are in line with the ones reported in Table 5 .

In sum, the results show that (i) girls are significantly more likely to engage in purging behavior than boys, (ii) girls' purging behavior is strongly affected by their female peers' BMI, whereas boys' behavior does not show a significant association with group BMI. This 
evidence is consistent with the epidemiological literature documenting that EDs are rare among males and follows a different rationale, less concerned with weight and most likely linked to idealized masculine shape (Darcy et al., 2012). ${ }^{20}$ In the rest of the paper, we will focus our analysis on girls, and define the reference group as the set of female students in the same grade and school. That is, for each female student $i$, our main variable of interest is the average BMI of peers of the same gender in her grade and school after eliminating student $i$ from the distribution.

We proceed in the next Section with the investigation of the channels that may be responsible for our main result: the negative and strong effect of girls' BMI on their female peers' probability of purging during high school.

\section{Exploring Mechanisms}

We begin by estimating model (1) with the restriction $\theta_{1}=-\theta_{2}$. This restriction, which is not rejected by our data, implies that what matters for the development of EDs is not only the absolute individual BMI but also the individual BMI relative to the one of the peers. We thus consider a restricted version of model (1), where the target variable is a measure of relative BMI, i.e. the log ratio between individual BMI and group BMI, ${ }^{21}$

$$
y_{i g s}=\alpha_{g}+\beta_{s}+x_{i s g}^{\prime} \gamma+\theta\left(b m i_{i s g}-\overline{b m i}_{i s g}\right)+\epsilon_{i g s} .
$$

The estimated coefficient $\theta$ reveals the magnitude of social concerns. It is reported in column (1) of Table 7, which includes the same set of controls as column (4) of Table 5. The point estimate of the coefficient of the relative BMI indicates that a 10 percent increase in the ratio of individual BMI to group BMI is associated with an increase of 0.9 percentage point in the probability of purging one year later. The size of the coefficient is again rather large.

Our hypothesis is that this finding is the result of interpersonal comparisons that generate distorted self-perceptions, for example when individuals perceive themselves as heavier than they actually are. To test this pathway one would need to observe that: (i) those with an

\footnotetext{
${ }^{20}$ Regarding AN, most studies find a 10:1 female-to-male prevalence ratio (Lindblad et al., 2006).

${ }^{21}$ Blanchflower et al. (2009) use the ratio between individual BMI and the BMI of the reference group, here defined as individuals of same gender and age living in the same country.
} 
upward distorted self-perception belong to a group with peers who are thinner; and (ii) our results are driven by students with upward distortion.

The Add Health provides a unique opportunity to investigate (i) and (ii) because it contains information on perceived body image, thus allowing us to compare real body size (as measured by the BMI) with perceived body size. Specifically, the Add Health survey asks "How do you think of yourself in terms of weight?". Answers to this question are coded 1 if the respondent reports being very underweight; 2 if slightly underweight; 3 if about the right weight; 4 if slightly overweight; and 5 if very overweight, in line with the five WHO categories (VUW, UW, NW, OW, and OB). Using information on actual body size, we can thus assess whether an individual has a distorted body image, measured as the difference between perceived and actual body size. We construct three indicators of distorted self-perception. First, "upward distortion", is a dummy variable that is equal to 1 if the perceived body weight falls in a category that is greater than the actual BMI class (which is the case for around 25 percent of individuals in our sample), and 0 otherwise. Second, "downward distortion", is a dummy variable that is equal to 1 if the perceived body weight falls in a category that is lower than the actual BMI class (which is the case for around 15 percent of individuals in our sample), and 0 otherwise. Third, "no distortion", is a dummy variable that is equal to 1 if the perceived body weight falls in the same category as the actual BMI class, and 0 otherwise.

In Figure 3 panel (a) we inspect the relationship between distorted self-perception and the average BMI in the reference group. ${ }^{22}$ It is immediately evident that as the body size of the reference group increases, the probability of reporting a self-perception distorted upward decreases and the probability of reporting a self-perception distorted downward increases. In other words, individuals are less likely to perceive themselves as heavier when they face peers with relatively higher body size. This evidence supports statement (i). In Figure 3 panel (b), we show the distribution of purging among girls with different self-perceptions of their body size. It is noteworthy that girls who believe themselves to be heavier (than what they actually are) are about twice as likely to engage in purging behavior than those with a correct

\footnotetext{
${ }^{22}$ We plot the predicted probabilities of having a distorted body image (upward or downward) as a function of group BMI using a logit regression.
} 
perception of their body weight. The likelihood of purging for girls who perceive themselves as thinner than they actually are is almost zero. This evidence supports statement (ii).

We further explore this evidence in Table 7, columns (2)-(4). In column (2), we estimate model (2) using the upward distortion indicator as the dependent variable. The results shows that the relative BMI coefficient is positive and statistically significant, confirming that the higher the distance from the average BMI of the reference group, the higher the probability of purging. In column (3) we keep our indicator of purging as the dependent variable in model (2) and include an interaction term between group BMI and our indicators of distorted self-perception. The results reveal that our evidence is driven by girls with an upward distortion, that is those who perceive themselves to be heavier than what they actually are. As a way to provide supporting evidence that a distorted body image mediates the effect of relative BMI on purging, in column (4) we include the indicator of upward distortion as an additional control variable. The results confirm our hypothesis: the magnitude of the estimated coefficient of relative BMI notably decreases and is no longer statistically significant.

We next consider whether relative BMI is associated with symptoms of emotional distress and feelings of social exclusion, and whether those in turn contribute to the pathway leading to the onset of EDs. We investigate the empirical salience of this theory in Table 8. Panel (a) displays the estimated coefficients of relative BMI when we estimate the model in equation (2) using as outcomes: whether the respondent has received psychological counseling (column (1)), whether she feels depressed (column (2)), whether she feels she is doing the right thing (column (3)), and whether she feels she is socially accepted (column (4)). ${ }^{23}$ The regressions reported in the different columns are based on (slightly different) sample sizes due to a different occurrence of missing values for these outcomes.

\footnotetext{
23 "Psychological counseling" is a dummy variable that is constructed using answers to the question: "In the past year, have you received psychological or emotional counseling?". The variable is coded $1=$ yes and 0 otherwise. "Feel depressed" is constructed using responses to the question: "How often you felt depressed during the past week", coded as $0=$ never or rarely, $1=$ sometimes, $2=$ a lot of times, and $3=$ most of the time. "Doing right" and "Socially accepted" are categorical variables that are constructed using answers to the statements: "You feel like you are doing everything just about right" and "You feel socially accepted", respectively. The variables are coded as $1=$ strongly disagree, $2=$ disagree, $3=$ neither agree nor disagree, $4=$ agree, and $5=$ strongly agree. All information is from the Wave I in-home survey. While "Psychological counseling" and "Feel depressed" have 1 missing value, "Doing right" and "Socially accepted" have 6 missing values for the individuals in our sample.
} 
Perhaps unsurprising, we find that the estimated coefficient of relative BMI is statistically significant and of the expected sign. For example, the probability of having received psychological counseling is increasing in relative BMI and statistically significant. This means that the likelihood of having received psychological counseling increases as the difference between $b m i$ and $\overline{b m i}$ becomes larger, that is when the girl is heavier than her female schoolmates. Panel (b) of Table 8 reports the result of the benchmark regression when including these variables as additional controls. The results shows that the point estimate of group BMI remains roughly unaffected, suggesting that proxies for emotional distress are not acting as mediators for the relationship between group BMI and purging. In summary, our results indicate that interpersonal comparisons among girls act as a channel for the onset of EDs through a student's development of her own body image. And this body image is distorted upward among those who interact more with thinner girls.

\section{Robustness Checks}

We begin our battery of robustness checks by determining if our estimates are sensitive to the inclusion of reference group characteristics, in particular the family characteristics of peers. It could be the case, for example, that peers' family disruptions, rather than their BMI, is key for the onset of EDs and that the omission of this contextual variable is driving our findings of a negative effect of group BMI. Peers' parental obesity could also be an important omitted variable. If teenagers have peers' parents as role models, then parents rather than peers are the important reference group for social comparisons. Table A.2 shows the results of our analysis when we add the fraction of peers with married parents (column (1)); the fraction of peers whose parental education is "Less than college" and the fraction of peers whose parental education is "College+" (column (2)); and the fraction of peers with at least an obese parent (column (3)). The results reveal that both the coefficients of individual BMI and group BMI remain stable when we include these controls in the regressions.

We next include other family background controls at both the individual and group levels in our model. The results are contained in Table A.3. We include the presence of alcohol at home (column (1)), if the parents receive family planning counseling or services (column 
(2)), and a number of proxies of the quality of the child-parent relationship. Specifically, we use an index of satisfaction of the respondent' relationship with her mother (column (3)), an index of whether the respondent feels that her parents care about her (column (4)), and how many of the last seven days there was at least one parent in the room while eating evening meals (column (5)). ${ }^{24}$ As in Table 8, the estimates in each column are based on slightly different sample sizes due to a different number of missing values in the additional control we consider in each specification. Notably, the estimated coefficients of individual BMI and group BMI remain quite stable across all specifications. Moreover, the estimated coefficients are significant and of the expected sign for all of the additional controls. For example, the adolescents in our sample are, on average, more likely to purge if parents received family counseling. On the contrary, proxies for a good child-parent relationship are negatively and significantly associated with purging. These results are in line with the evidence that family exposure to stress is a risk factor for the development of ED symptoms, while satisfaction with child-parent relationship is a protective factor (see e.g., Allen et al., 2014, and references therein). None of the estimated coefficients for the additional controls at the peer level are statistically significant. A complete list of results can be found in Table B.1 in the Online Appendix. In column (6) we consider infant breastfeeding as a proxy for early life eating practices. Observational studies have documented that breastfeeding contributes to a positive eating attitude and healthy eating behavior later on. ${ }^{25}$ The estimates reveal that the inclusion of this variable leaves our qualitative evidence roughly unchanged, and

\footnotetext{
24 "Alcohol at home" is a dummy variable constructed using responses to the question: "Is alcohol easily available to you in your home?", coded as $1=$ yes, and 0 otherwise. This variable has 31 missing values for individuals in our sample. "Family counseling" is a dummy variable taking the value of 1 if the respondent answers yes to the question: "In the past year, have you received family planning counseling or services?". This variable has 31 missing values for individuals in our sample. "Mother relationship satisfaction" is a categorical variable constructed using the responses to the question: "Overall, are you satisfied with your relationship with your mother ?", coded as $1=$ strongly disagree, $2=$ disagree, $3=$ neither agree nor disagree, $4=$ agree, and $5=$ strongly agree. This variable has 63 missing values for individuals in our sample "Parents care" is a categorical variable constructed from responses to the question: "How much do you feel that parents care about you?", coded as $1=$ not at all, $2=$ very little, $3=$ somewhat, $4=$ quite a bit, and $5=$ very much. This variable has 5 missing values for individuals in our sample "Dinner together" is a categorical variable constructed using the responses to the question: "On how many of the past 7 days was at least one of your parents in the room with you while you ate your evening meal?", coded from $0=$ no days to $7=7$ days. This variable has 4 missing values for individuals in our sample. Information for all these variables is from the Wave I in-home survey.

${ }^{25}$ This question is asked in the parental questionnaire of Wave I. The variable is constructed from responses to the answer: "For how long was respondent breastfed?", coded as 1 if the child was breastfed for more than 3 months and 0 otherwise. This variable has 42 missing values for individuals in our sample.
} 
that infant breastfeeding is not significantly associated with purging. In columns (7)-(10) we next consider sports activities, eating habits, risky behavior, and residential neighborhood characteristics, as all of these factors may be associated with purging behavior. For example, people engaged in competitive physical activities (e.g., sports, fitness, and dance) display high levels of body dissatisfaction, disordered eating, and EDs. Especially among females, the pursuit of "optimal" fitness and body shape for sport or dance may trigger EDs (Johnson et al., 1999; Jankowski et al., 2014, and references therein). Risk attitudes may also be correlated with purging behavior. According to the National Center on Addiction and Substance Abuse, the substances most frequently abused by individuals with EDs or with sub-clinical symptoms of EDs are alcohol, illicit drugs, and tobacco. ${ }^{26}$ We construct an indicator of the number of times the respondent plays an active sport and/or exercises per week, an indicator of how often she eats unhealthy food (pie, cookies, doughnuts or cake), a risky behavior index based on respondent's consumption of alcohol, and an indicator of the residential building quality. ${ }^{27}$ While athletic activities are not associated with purging behavior, the results show a negative correlation with respondent bad eating habits. In line with our expectations, we find that alcohol consumption is positively associated with purging. ${ }^{28}$ Finally, aligned with the non-significant association between purging and family income (see e.g. Table 5, column (4)), we find that the estimated effect of our indicator of neighborhood quality is not statistically significant. Importantly for the purpose of this

\footnotetext{
26 "Food for Thought: Substance Abuse and Eating Disorders", The National Center on Addiction and Substance Abuse (2003).

27 "Sport Activity" is an indicator constructed from the responses to the questions: "During the past week, how many times did you play an active sport, such as baseball, softball, basketball, soccer, swimming, or football?" and "During the past week, how many times did you do exercise, such as jogging, walking, karate, jumping rope, gymnastics or dancing?". Answers to both questions are coded as $3=5$ or more times, $2=3$ or 4 times, $1=1$ or 2 times neither agree nor disagree, and $0=$ never. "Sport Activity" takes the value of 1 if the answers to either the first or the second questions are equal to 1,2 or 3. "Junk food" is a dummy variable constructed from responses to the question: "How often did you eat cookies, doughnuts, pie, or cake yesterday?", coded as $1=$ ate twice or more, and $0=$ ate once or didn't eat. "Alcohol consumption" is constructed using the answers to the questions "Over the past 12 months, on how many days did you drink five or more drinks in a row?". This variable has 5 missing values for individuals in our sample. "Building quality" is a categorical variable that is based on the interviewer's responses to the question: "How well kept is the building in which the respondent lives?". This variable takes the value 1 if the respondent reports very well kept; 2 if fairly well kept (needs cosmetic work); 3 if poorly kept. This variable has 16 missing values for individuals in our sample. Information for all these variables is from the Wave I in-home survey.

${ }^{28}$ Using data from 3,000 adult women in 1992 in the US, Dansky et al. (2000) document a positive correlation between alcohol abuse and BN diagnosis. See also Cawley and Ruhm (2011), for a summary of the literature on the consequences of risky health behaviors.
} 
exercise, results show that the estimated coefficient of both individual BMI and group BMI change minimally when we add any of these controls, indicating that there are no important sources of bias due to omitted factors correlated with the vast array of eating and life style habits considered.

Given the small number of EDs, we next investigate whether our results are sensitive to distributional assumptions. The results of our analysis when using a logit model are shown in Table A.5. The results reveal that the estimated coefficients of both group BMI and own BMI retain both the statistical significance and sign of the OLS estimates in Table 6. ${ }^{29}$ Observe that given the large number of schools, the maximum likelihood estimator of a standard logit model may be inconsistent due to the incidental parameter problem (Neyman and Scott, 1948). For this reason, we report the estimates of a conditional logit model (Andersen, 1970)..$^{30}$

A possible concern with our analysis is that our measure of group BMI might be contaminated by measurement error since the Add Health survey asks sensitive questions about health and risky behavior only to the students in the in-home sample. This is likely to be true. However, because the students in the in-home sample are randomly sampled from the school rosters, the OLS estimates are likely to be biased towards zero under classical measurement error. As a result, our estimates would be conservative. In order to check if this is indeed the case and to quantify the attenuation bias, we replicate the results of Table 6 for the "saturated sample". The Add Health "saturated sample" consists of the students belonging to the subset of schools where all of their students are also interviewed at home using the in-home questionnaire (16 schools). Table A.4 reports the estimation results of our main regression for this subsample. The point estimate of the group BMI coefficient remains statistically significant and more than doubles in magnitude. This is evidence of classical measurement error and large attenuation bias, in line with our expectations.

Finally, we use a simulation exercise following Athey and Imbens (2017) to study whether our results could have occurred by chance. We calculate the likelihood of obtaining the

\footnotetext{
${ }^{29}$ We have also estimated model (1) where group BMI is expressed in levels, rather than in logs. The results remain qualitatively unchanged. They are available upon request.

${ }^{30}$ Marginal effects cannot be computed since this would require to specify a marginal distribution for the school fixed effects.
} 
observed treatment effects by chance by generating randomness in the exposure of individuals to a given cohort composition. For each student, we replace the actual cohort BMI with that of a randomly selected cohort from the same school. We repeat this procedure 1,000 times, and run the full specification in Table 6 (column (3)). The distribution of the estimated coefficients of our main variable group BMI are reported in Figure A.3. The graph shows that these estimates are small and centered around zero. The red vertical line indicates the estimated treatment effect we obtained in Table 6 (column (3)). This is sizable and located in the lower value of the distribution of placebo estimates, providing evidence that this is unlikely to have occurred by chance. The share of estimates that is larger in absolute value than the red line (actual treatment) represents the randomization-based p-value. As can be seen in the figure, the randomization-based p-value is roughly 0.05 comparable to the sampling-based p-values of Table 6, column (1) (0.021).

\section{Further Results}

The intensity of the concerns about one's own body image generated from peer comparisons may be different depending on how far an individual is from her peers in terms of socio-demographic characteristics. According to the social comparison theory, first proposed in 1954 by psychologist Leon Festinger, people evaluate their own abilities and beliefs by comparing themselves with those who they believe are better than them (upward comparison) and with those who are worse off than themselves (downward comparison). Individuals comparing themselves to someone better off are motivated by the desire to improve their current status and subsequently look for ways to achieve similar results. ${ }^{31}$

We examine heterogeneity in the main results for three types of individuals: (i) those with a value of a characteristic at least one standard deviation below the mean value of the reference group, (ii) those with the value around the mean value of the group (within one standard deviation), and (iii) those with the value at least one standard deviation above the mean value of the reference group. We consider the following characteristics: BMI, family income, parental education, student verbal ability as measured by PVT test score, and

\footnotetext{
${ }^{31}$ See also Wheeler et al. (1982) and Wood (1996).
} 
student popularity. The Add Health has the unique ability to measure student popularity since the in-school questionnaires asks all pupils to identify their best friends from a school roster (up to five boys and five girls). Student popularity is defined as the total number of nominations received by the respondent. ${ }^{32}$ We estimate the following model:

$$
y_{i g s}=\alpha_{g}+\beta_{s}+x_{i s g}^{\prime} \gamma+\theta b m i_{i s g}+\left(\mu_{1}+\sum_{j=2}^{3} \mu_{j} I_{j}\right) \overline{b m i}_{i s g}+\epsilon_{i g s}
$$

where $\mu_{1}$ is the group BMI coefficient for type-(i) individuals, $\mu_{1}+\mu_{2}$ for type-(ii) individuals, and $\mu_{1}+\mu_{3}$, for type-(iii) individuals. $I_{j}$ is an indicator function that is equal to 1 if the individual is of type $j$, where $j=2,3$. Table 9 reports the differential effects for the three categories, $\mu_{1}, \mu_{1}+\mu_{2}$, and $\mu_{1}+\mu_{3}$, for the characteristics listed above.

Two results emerge from this table. First, looking at socio-economic characteristics (columns (2)-(5)), it appears that the effects of interpersonal comparison are in fact hierarchical: they are at work only for girls who are less (verbally) able, less popular and with less educated parents than their peers. Family income is a notable exception to this pattern, since in this case the effects of interpersonal comparison are stronger for girls within the same income class as their peers. Overall, this evidence corroborates the above-mentioned view in psychology that social comparisons are often made toward others who are perceived to be superior to themselves in terms of specific attributes, and identifies some of those traits. Second, looking at column (1), it appears that the girls influenced by interpersonal comparisons with peers are those with a BMI at least one standard deviation above the average of their peers. For these girls, the semi-elasticity of group BMI is more than 3 times larger than the one in column (1) of Table 6 (-0.68 vs -0.20). This evidence suggests that girls exposed to a high fraction of thinner girls are especially at risk of developing EDs.

To further understand this result, we perform two exercises: (i) we depart from the linearin-means specification of the model to assess distributional effects for our main variable, and (ii) we use an alternative definition of reference group: the fraction of underweight female

\footnotetext{
${ }^{32}$ The limit in the number of nominations is not binding, not even by gender. Less than 1 percent of the students in our sample report a list of ten best friends, less than 3 percent report a list of 5 boys, and roughly 4 percent a list of 5 girls. Because roughly 20 percent of the students do not nominate any friends and another 20 percent list friends that cannot be tracked, we lose 783 girls in this regression.
} 
peers (rather than their average BMI). The results of these analyses are summarized in Table 10. Column (1) reports the results from Table 6, column (1), as a benchmark, while in column (2) we include dummies corresponding to terciles of the distribution of group BMI. The omitted category is whether this variable is in the bottom tercile of the distribution. Results reveal a statistical difference at the second and third tercile of the distribution of group BMI and an increasing magnitude of the estimated effect. This evidence indicates that the probability of purging is higher for the girls who are exposed to female schoolmates whose average BMI is low (i.e. in the first tercile of the distribution) than for those with schoolmates who are heavier (i.e. in the third tercile of the distribution).

In column (3), we then use an alternative definition of reference point: the fraction of girls in a given cohort and school who are underweight (after eliminating girl $i$ from the distribution). The estimated effect is quite large. If the fraction of UW in the group increases by 10 percent, the likelihood of purging increases by 1 percent. When the fraction of underweight peers enters non-linearly (column (4)), the results show that the effect for girls exposed to a fraction of underweight peers in the top tercile is stronger than the effect for those with female schoolmates in the bottom tercile of the distribution.

This evidence further supports the theory that appearance-based comparisons may be a potent form of social comparisons influencing the onset of EDs among adolescent girls, and reveals that the target group for these comparisons are peers who are perceived to have "better" physical features. This is in line with recent experimental studies in psychology. For example, in a field experiment on 454 college women who were enrolled in an introductory psychology course in a private university, Arigo et al. (2014) document that women who were newly above the clinical threshold for eating pathology at follow-up exhibited stronger tendencies toward upward appearance comparisons than women who were below the threshold nine months earlier. Taken as a whole, our analysis validates the view that evaluative comparisons likely concentrate on specific sub-groups of fellow classmates, and that those social comparisons are important for the onset of EDs. In particular, girls tend to consider extremely thin female peers as reference points and are likely to engage in purging behavior to achieve similar results. 


\section{Conclusions}

Despite the prevalence of EDs in the United States, relatively little is known about the mechanisms underlying the diffusion of EDs and the efficacy of government programs in preventing or treating them (Shaw et al., 2009). ${ }^{33}$ In this paper we focus on a particular channel that might be relevant in the development of EDs: purging influenced by the peers' body size through interpersonal comparisons. The underlying assumption is that adolescents not only care about their absolute BMI but also their BMI relative to their peers. While a number of observational studies in social psychology have studied the relationship between relative BMI and body dissatisfaction, only a few of them discussed their association with EDs. Identifying the effect of relative BMI on purging is challenging because it requires plausibly exogenous variation in group BMI. In this paper, identification relies on withinschool, across cohort variation in schoolmates' BMI, which is proved to be quasi-random. We show that interpersonal comparisons play an important role for the onset of EDs of teenage girls and that the direction in which peer influence is transmitted is hierarchical: from more popular girls with higher socio-economic status to less popular girls with lower socio-economic status. Interpersonal comparisons operate through the formation of distorted self-perceptions during adolescence. Notably, teenage girls with thinner female peers perceive themselves as more overweight than they actually are. This perception in turn is important for whether they start purging and consequently develop EDs later in life.

In sum, our findings indicate that the onset of EDs hinges on misperceptions of actual body size that spring from social comparisons. While it seems unrealistic to propose educational programs that would eliminate comparisons among fellow students, the programs should rather foster girls to cope with the potentially negative effects of interpersonal comparisons and preserve self-esteem and self-worth. Today, most public health interventions fighting the onset of EDs focus on healthy eating and nutrition; media exposure and sociocultural pressures to be thin; body acceptance and body satisfaction (Chao et al., 2014). Our results suggest that such programs should not only discuss the exposure to prevalent

\footnotetext{
${ }^{33}$ While the age-adjusted costs for the treatment of EDs per year is comparable to the costs of schizophrenia treatment (Striegel-Moore et al., 2000), research dollars spent on EDs was just $\$ 0.93$ per affected individual in 2011 , compared to an average of $\$ 88$ and $\$ 81$ spent on Alzheimer's and schizophrenia, respectively (National Institute for Mental Health, 2011).
} 
appearance ideal in mass media (and how to challenge pressures to conform to unrealistic beauty ideals), but also how to maintain positive views when adolescents compare themselves to their peers, who are the reference points they face on a daily basis. ${ }^{34}$ Further, as not all individuals might react in the same way to interpersonal comparisons, additional research is needed to understand why some individuals might be affected and others not.

Finally, our results point to potentially harmful side effects of programs fighting obesity. In fact, programs centred on anti-obesity messages and/or BMI measurement in schools may trigger shame and distress, enhance the negative effects of social comparisons, and increase rather than shrink unhealthy weight control practices, such as purging. Indeed, the Centers for Disease Control and Prevention (CDC) have recently noted that school-based BMI screening programs might stigmatize students and lead to harmful behaviors. ${ }^{35}$ Our evidence supports the CDC recommendation that schools introducing BMI measurement programs should not only promote healthful eating and healthy weight management (e.g., regular physical activity), but also have in place a safe and supportive environment for students of all body sizes. Specifically, in order to minimize the risk of intensifying dissatisfaction with body image and pressure to engage in harmful weight loss practices, promoting body acceptance and ways to buffer the potentially negative effects of social comparisons can reduce disordered eating symptoms especially among female students.

\section{References}

Akerlof, G. A. and Kranton, R. E. (2000). Economics and identity, The Quarterly Journal of Economics 115(3): 715-753.

Allen, K. L., Gibson, L. Y., McLean, N. J., Davis, E. A. and Byrne, S. M. (2014). Maternal

\footnotetext{
${ }^{34}$ In the United States, only two prevention programs have significantly reduced the risk for future onset of EDs so far: the Body Project and the Healthy Weight Program (Stice et al., 2013). While the Healthy Weight Program pursues lasting improvements in dietary intake and physical activity, the Body Project aims to inform participants about the costs of pursuing the thin ideal standard of female beauty and ways to cope with pressures to conform to unrealistic standards of beauty.

${ }^{35}$ See the article titled "Body Mass Index (BMI) Measurement in Schools", written by a CDC panel and available at: https://www.cdc.gov/healthyschools/obesity/bmi/bmi_measurement_schools.htm. Accessed December 2018.
} 
and family factors and child eating pathology: Risk and protective relationships, Journal of eating disorders 2(1): 11.

Altonji, J. G., Elder, T. E. and Taber, C. R. (2005). Selection on observed and unobserved variables: Assessing the effectiveness of catholic schools, Journal of political economy 113(1): 151-184.

American Psychiatric Association (2013). Diagnostic and statistical manual of mental disorders (revised 5th ed.).

Andersen, E. B. (1970). Asymptotic properties of conditional maximum-likelihood estimators, Journal of the Royal Statistical Society. Series B (Methodological) pp. 283-301.

Angrist, J. D. and Lang, K. (2004). Does school integration generate peer effects? evidence from boston's metco program, American Economic Review 94(5): 1613-1634.

Arigo, D., Schumacher, L. and Martin, L. M. (2014). Upward appearance comparison and the development of eating pathology in college women, International Journal of Eating Disorders 47(5): 467-470.

Athey, S. and Imbens, G. W. (2017). The econometrics of randomized experimentsa, Handbook of Economic Field Experiments, Vol. 1, Elsevier, pp. 73-140.

Balsa, A. and Díaz, C. (2018). Social interactions in health behaviors and conditions, Oxford Research Encyclopedia of Economics and Finance, Oxford University Press.

Battaglini, M., Bénabou, R. and Tirole, J. (2005). Self-control in peer groups, Journal of Economic Theory 123(2): 105-134.

Battaglini, M., Díaz, C. and Patacchini, E. (2017). Self-control and peer groups: An empirical analysis, Journal of Economic Behavior \& Organization 134: 240-254.

Becker, A. E., Franko, D. L., Speck, A. and Herzog, D. B. (2003). Ethnicity and differential access to care for eating disorder symptoms, International Journal of Eating Disorders 33(2): 205-212. 
Bifulco, R., Fletcher, J. M. and Ross, S. L. (2011). The effect of classmate characteristics on post-secondary outcomes: Evidence from the add health, American Economic Journal: Economic Policy 3(1): 25-53.

Blanchflower, D. G., Van Landeghem, B. and Oswald, A. J. (2009). Imitative obesity and relative utility, Journal of the European Economic Association 7(2-3): 528-538.

Brown, B. B., Mory, M. S. and Kinney, D. (1994). Casting adolescent crowds in a relational perspective: Caricature, channel, and context., Vol. 6, In R. Montemayor, G. R. Adams, T. P. Gullotta (Eds.), Advances in adolescent development: An annual book series. Personal relationships during adolescence. Sage Publications, Inc.

Bruch, H. et al. (1974). Eating disorders. Obesity, anorexia nervosa, and the person within., Routledge \& Kegan Paul.

Bursztyn, L. and Jensen, R. (2017). Social image and economic behavior in the field: Identifying, understanding, and shaping social pressure, Annual Review of Economics 9: 131-153.

Buunk, A. P. and Gibbons, F. X. (2007). Social comparison: The end of a theory and the emergence of a field, Organizational Behavior and Human Decision Processes 102(1): 3-21.

Card, D., Mas, A., Moretti, E. and Saez, E. (2012). Inequality at work: The effect of peer salaries on job satisfaction, American Economic Review 102(6): 2981-3003.

Cawley, J. (2015). An economy of scales: A selective review of obesity's economic causes, consequences, and solutions, Journal of health economics 43: 244-268.

Cawley, J. and Ruhm, C. J. (2011). The economics of risky health behaviors, Handbook of health economics, Vol. 2, Elsevier, pp. 95-199.

Chao, A., Grilo, C. M., White, M. A. and Sinha, R. (2014). Food cravings, food intake, and weight status in a community-based sample, Eating behaviors 15(3): 478-482.

Charité, J., Fisman, R. and Kuziemko, I. (2015). Reference points and redistributive preferences: Experimental evidence, Technical report, NBER Working Paper No. 21009. 
Cooper, Z. and Fairburn, C. (1987). The eating disorder examination: A semi-structured interview for the assessment of the specific psychopathology of eating disorders, International Journal of Eating Disorders 6(1): 1-8.

Costa-Font, J. and Jofre-Bonet, M. (2013). Anorexia, body image and peer effects: Evidence from a sample of european women, Economica 80(317): 44-64.

Crago, M., Shisslak, C. M. and Estes, L. S. (1996). Eating disturbances among american minority groups: A review, International Journal of Eating Disorders 19(3): 239-248.

Dansky, B. S., Brewerton, T. D. and Kilpatrick, D. G. (2000). Comorbidity of bulimia nervosa and alcohol use disorders: Results from the national women's study, International Journal of Eating Disorders 27(2): 180-190.

Darcy, A. M., Doyle, A. C., Lock, J., Peebles, R., Doyle, P. and Le Grange, D. (2012). The eating disorders examination in adolescent males with anorexia nervosa: How does it compare to adolescent females?, International Journal of Eating Disorders 45(1): 110-114.

Dieye, R. and Fortin, B. (2017). Gender peer effects heterogeneity in obesity, Technical report, CIRANO WP 2017S-03.

Dijkstra, P., Kuyper, H., Van der Werf, G., Buunk, A. P. and van der Zee, Y. G. (2008). Social comparison in the classroom: A review, Review of educational research 78(4): 828879 .

Eagles, J. M., Johnston, M. I. and Millar, H. R. (2005). A case-control study of family composition in anorexia nervosa, International Journal of Eating Disorders 38(1): 49-54.

Exley, C. L. and Terry, S. J. (2017). Wage elasticities in working and volunteering: The role of reference points in a laboratory study, Management Science .

Fairburn, C. G. and Cooper, P. J. (1982). Self-induced vomiting and bulimia nervosa: An undetected problem., Br Med J (Clin Res Ed) 284(6323): 1153-1155.

Farber, H. S. (2008). Reference-dependent preferences and labor supply: The case of new york city taxi drivers, American Economic Review 98(3): 1069-82. 
Fehr, E. and Goette, L. (2007). Do workers work more if wages are high? evidence from a randomized field experiment, American Economic Review 97(1): 298-317.

Festinger, L. (1954). A theory of social comparison processes, Human relations 7(2): 117-140.

Fortin, B. and Yazbeck, M. (2015). Peer effects, fast food consumption and adolescent weight gain, Journal of health economics 42: 125-138.

Friesen, J. and Krauth, B. (2007). Sorting and inequality in canadian schools, Journal of public Economics 91(11-12): 2185-2212.

Goodman, A., Heshmati, A., Malki, N. and Koupil, I. (2014). Associations between birth characteristics and eating disorders across the life course: findings from 2 million males and females born in sweden, 1975-1998, American journal of epidemiology 179(7): 852-863.

Ham, J. C., Iorio, D. and Sovinsky, M. (2013). Caught in the bulimic trap? persistence and state dependence of bulimia among young women, Journal of Human Resources 48(3): $736-767$.

Hanushek, E. A., Kain, J. F., Markman, J. M. and Rivkin, S. G. (2003). Does peer ability affect student achievement?, Journal of applied econometrics 18(5): 527-544.

Hilbert, A., Pike, K. M., Goldschmidt, A. B., Wilfley, D. E., Fairburn, C. G., Dohm, F.A., Walsh, B. T. and Weissman, R. S. (2014). Risk factors across the eating disorders, Psychiatry Research 220(1-2): 500-506.

Hill, A. (2007). Obesity and eating disorders, Obesity reviews 8: 151-155.

Hoxby, C. (2000). Peer effects in the classroom: Learning from gender and race variation, Technical report, NBER Working Paper No. 7867.

Jankowski, G. S., Fawkner, H., Slater, A. and Tiggemann, M. (2014). "appearance potent"? a content analysis of uk gay and straight men's magazines, Body image 11(4): 474-481.

Johnson, C., Powers, P. S. and Dick, R. (1999). Athletes and eating disorders: The national collegiate athletic association study, International Journal of Eating Disorders 26(2): 179188. 
Jones, D. C. (2001). Social comparison and body image: Attractiveness comparisons to models and peers among adolescent girls and boys, Sex roles 45(9-10): 645-664.

Jones, D. C., Vigfusdottir, T. H. and Lee, Y. (2004). Body image and the appearance culture among adolescent girls and boys: An examination of friend conversations, peer criticism, appearance magazines, and the internalization of appearance ideals, Journal of adolescent research 19(3): 323-339.

Kass, A. E., Jones, M., Kolko, R. P., Altman, M., Fitzsimmons-Craft, E. E., Eichen, D. M., Balantekin, K. N., Trockel, M., Taylor, C. B. and Wilfley, D. E. (2017). Universal prevention efforts should address eating disorder pathology across the weight spectrum: Implications for screening and intervention on college campuses, Eating behaviors 25: 74-80.

Keel, P. K., Haedt, A. and Edler, C. (2005). Purging disorder: An ominous variant of bulimia nervosa?, International Journal of Eating Disorders 38(3): 191-199.

Lavy, V., Paserman, M. D. and Schlosser, A. (2012). Inside the black box of ability peer effects: Evidence from variation in the proportion of low achievers in the classroom, The Economic Journal 122(559): 208-237.

Lavy, V. and Schlosser, A. (2011). Mechanisms and impacts of gender peer effects at school, American Economic Journal: Applied Economics 3(2): 1-33.

Leahey, T. M., LaRose, J. G., Fava, J. L. and Wing, R. R. (2011). Social influences are associated with bmi and weight loss intentions in young adults, Obesity 19(6): 1157-1162.

Lindblad, F., Lindberg, L. and Hjern, A. (2006). Improved survival in adolescent patients with anorexia nervosa: A comparison of two swedish national cohorts of female inpatients, American Journal of Psychiatry 163(8): 1433-1435.

Littleton, H. L. and Ollendick, T. (2003). Negative body image and disordered eating behavior in children and adolescents: What places youth at risk and how can these problems be prevented?, Clinical child and family psychology review 6(1): 51-66. 
Liu, X., Patacchini, E. and Zenou, Y. (2014). Endogenous peer effects: Local aggregate or local average?, Journal of Economic Behavior \& Organization 103: 39-59.

Lockwood, P. and Kunda, Z. (1997). Superstars and me: Predicting the impact of role models on the self., Journal of personality and social psychology 73(1): 91.

Marques, L., Alegria, M., Becker, A. E., Chen, C.-n., Fang, A., Chosak, A. and Diniz, J. B. (2011). Comparative prevalence, correlates of impairment, and service utilization for eating disorders across us ethnic groups: Implications for reducing ethnic disparities in health care access for eating disorders, International Journal of Eating Disorders 44(5): 412-420.

Mas, A. (2006). Pay, reference points, and police performance, The Quarterly Journal of Economics 121(3): 783-821.

Miller, D. T., Turnbull, W. and McFarland, C. (1988). Particularistic and universalistic evaluation in the social comparison process., Journal of Personality and Social Psychology 55(6): 908 .

Mulders-Jones, B., Mitchison, D., Girosi, F. and Hay, P. (2017). Socioeconomic correlates of eating disorder symptoms in an australian population-based sample, PloS one 12(1): e0170603.

Myers, T. A. and Crowther, J. H. (2009). Social comparison as a predictor of body dissatisfaction: A meta-analytic review., Journal of abnormal psychology 118(4): 683.

Neyman, J. and Scott, E. L. (1948). Consistent estimates based on partially consistent observations, Econometrica: Journal of the Econometric Society 16(1): 1-32.

Olivetti, C., Patacchini, E. and Zenou, Y. (2018). Mothers, peers, and gender-role identity, Journal of the European Economic Association (Forthcoming).

Patacchini, E. and Venanzoni, G. (2014). Peer effects in the demand for housing quality, Journal of Urban Economics 83: 6-17.

Patacchini, E. and Zenou, Y. (2012). Ethnic networks and employment outcomes, Regional Science and Urban Economics 42(6): 938-949. 
Patacchini, E. and Zenou, Y. (2016). Social networks and parental behavior in the intergenerational transmission of religion, Quantitative Economics 7(3): 969-995.

Shaw, H., Stice, E. and Becker, C. B. (2009). Preventing eating disorders, Child and Adolescent Psychiatric Clinics 18(1): 199-207.

Steinhausen, H.-C., Gavez, S. and Winkler Metzke, C. (2005). Psychosocial correlates, outcome, and stability of abnormal adolescent eating behavior in community samples of young people, International Journal of Eating Disorders 37(2): 119-126.

Stice, E., Becker, C. B. and Yokum, S. (2013). Eating disorder prevention: Current evidencebase and future directions, International Journal of Eating Disorders 46(5): 478-485.

Stice, E. and Shaw, H. E. (2002). Role of body dissatisfaction in the onset and maintenance of eating pathology: A synthesis of research findings, Journal of psychosomatic research 53(5): 985-993.

Striegel-Moore, R. H., Dohm, F., Solomon, E., Fairburn, C. G., Pike, K. M. and Wilfley, D. E. (2000). Subthreshold binge eating disorder, International Journal of Eating Disorders $27(3): 270-278$.

Taylor, J. Y., Caldwell, C. H., Baser, R. E., Faison, N. and Jackson, J. S. (2007). Prevalence of eating disorders among blacks in the national survey of american life, International Journal of Eating Disorders 40(S3): S10-S14.

The National Center on Addiction and Substance Abuse (2003). Food for thought: Substance abuse and eating disorders.

Wheeler, L., Koestner, R. and Driver, R. E. (1982). Related attributes in the choice of comparison others: It's there, but it isn't all there is, Journal of Experimental Social Psychology 18(6): 489-500.

Wilson, G. T., Nonas, C. A. and Rosenblum, G. D. (1993). Assessment of binge eating in obese patients, International Journal of Eating Disorders 13(1): 25-33. 
Wood, J. V. (1996). What is social comparison and how should we study it?, Personality and Social Psychology Bulletin 22(5): 520-537.

Yakusheva, O., Kapinos, K. A. and Eisenberg, D. (2014). Estimating heterogeneous and hierarchical peer effects on body weight using roommate assignments as a natural experiment, Journal of Human Resources 49(1): 234-261. 


\section{Figures and Tables}

Figure 1: Measured versus Self-reported BMI

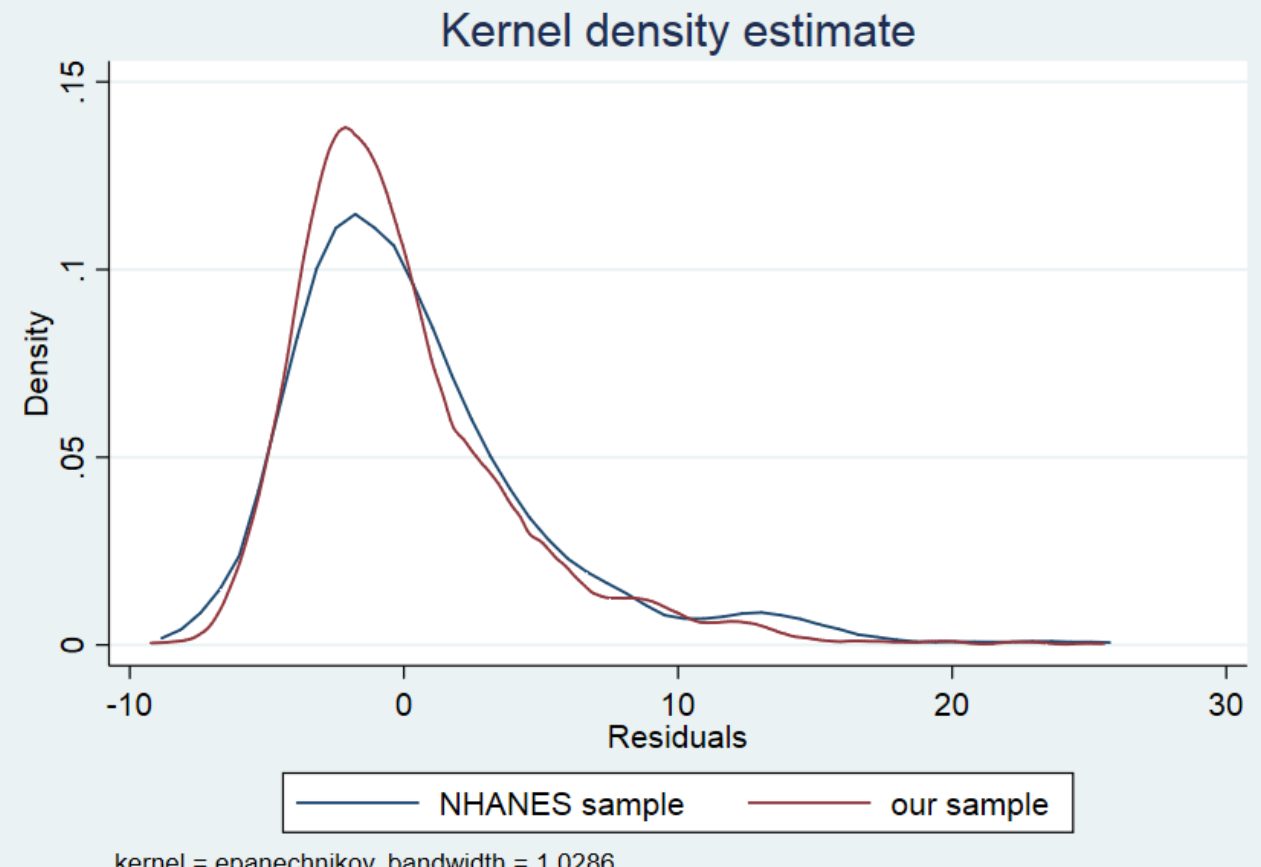

Notes. Residuals are estimated from a regression of BMI on gender, age and race dummies. BMI is constructed using self-reported height and weight in the Add Health survey. Measured BMI is constructed using the National Health and Nutrition Examination survey (NHANES 1999-2000). 
Figure 2: Purging, individual BMI, group BMI, and deviation of BMI
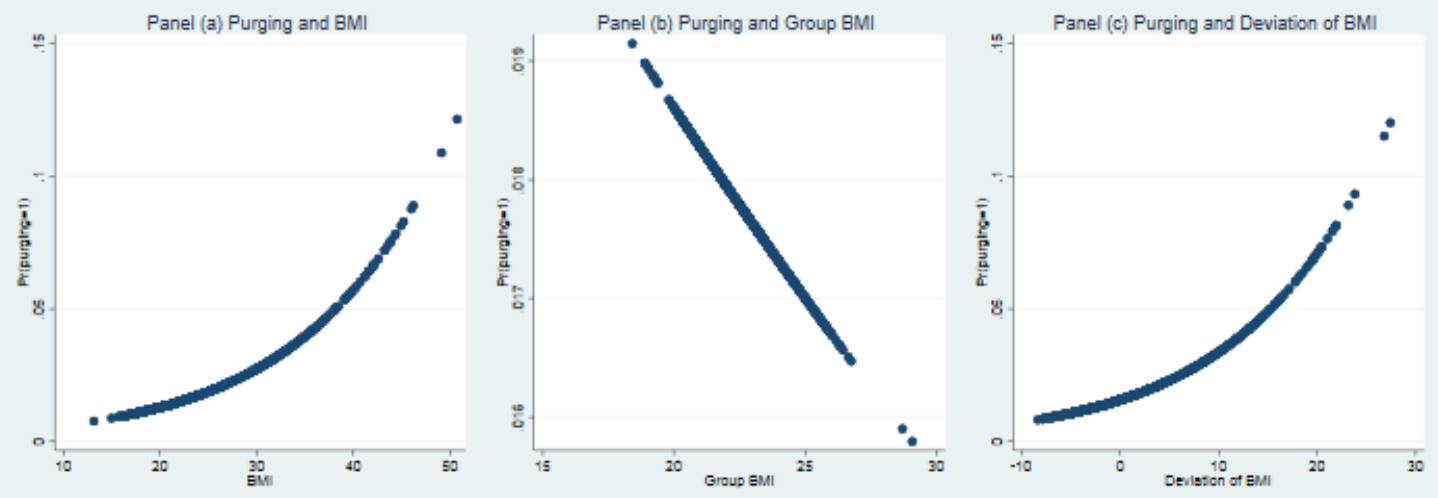

Notes. The purging indicator is equal to 1 if the respondent engages in at least one form of unhealthy weight control behavior (e.g., vomit, use laxatives, and use of dieting pills), and 0 otherwise. Group BMI is the average BMI in the reference group, that is the mean BMI of the leave-one-out distribution of students belonging to respondent's grade and school. Deviation of BMI is defined as the deviation of individual BMI from the average BMI in the reference group. 
Figure 3: Purging, group BMI and distorted self-perception
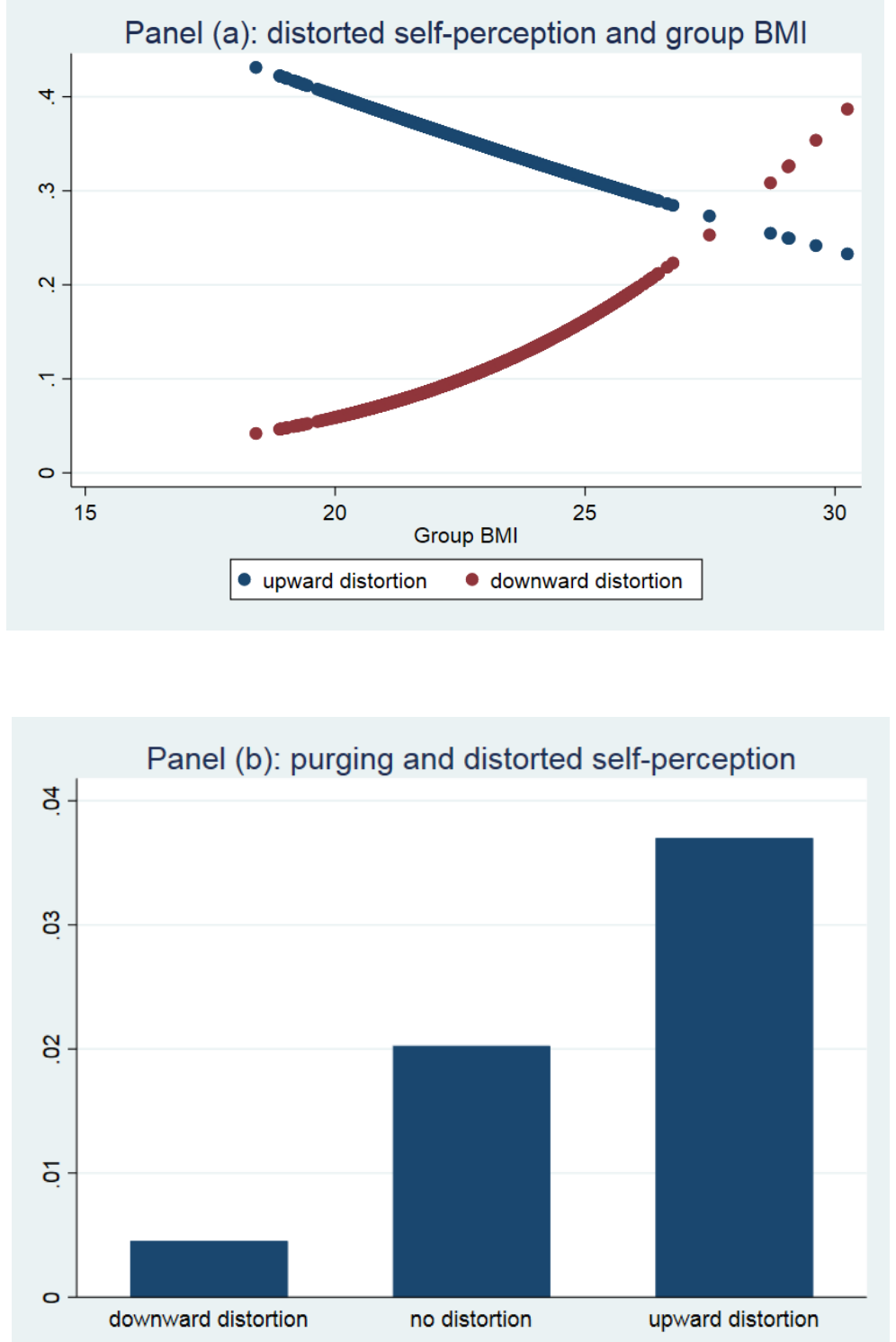

Notes. We construct three indicators of distorted self-perception. The first "upward distortion" is a dummy variable that is equal to 1 if the perceived body weight falls in a category that is greater than the actual BMI class (that is true for around 25 percent of individuals in our sample), and 0 otherwise. The second "downward distortion" is a dummy variable, which is equal to 1 if the perceived body weight falls in a category that is lower than the actual BMI class (around 15 percent of individuals in our sample), and 0 otherwise. The third "no distortion" is a dummy variable, which is equal to 1 if the perceived body weight falls in the same category as the actual BMI class (around 60 percent of individuals in our sample), and 0 otherwise. 
Table 1: Summary statistics

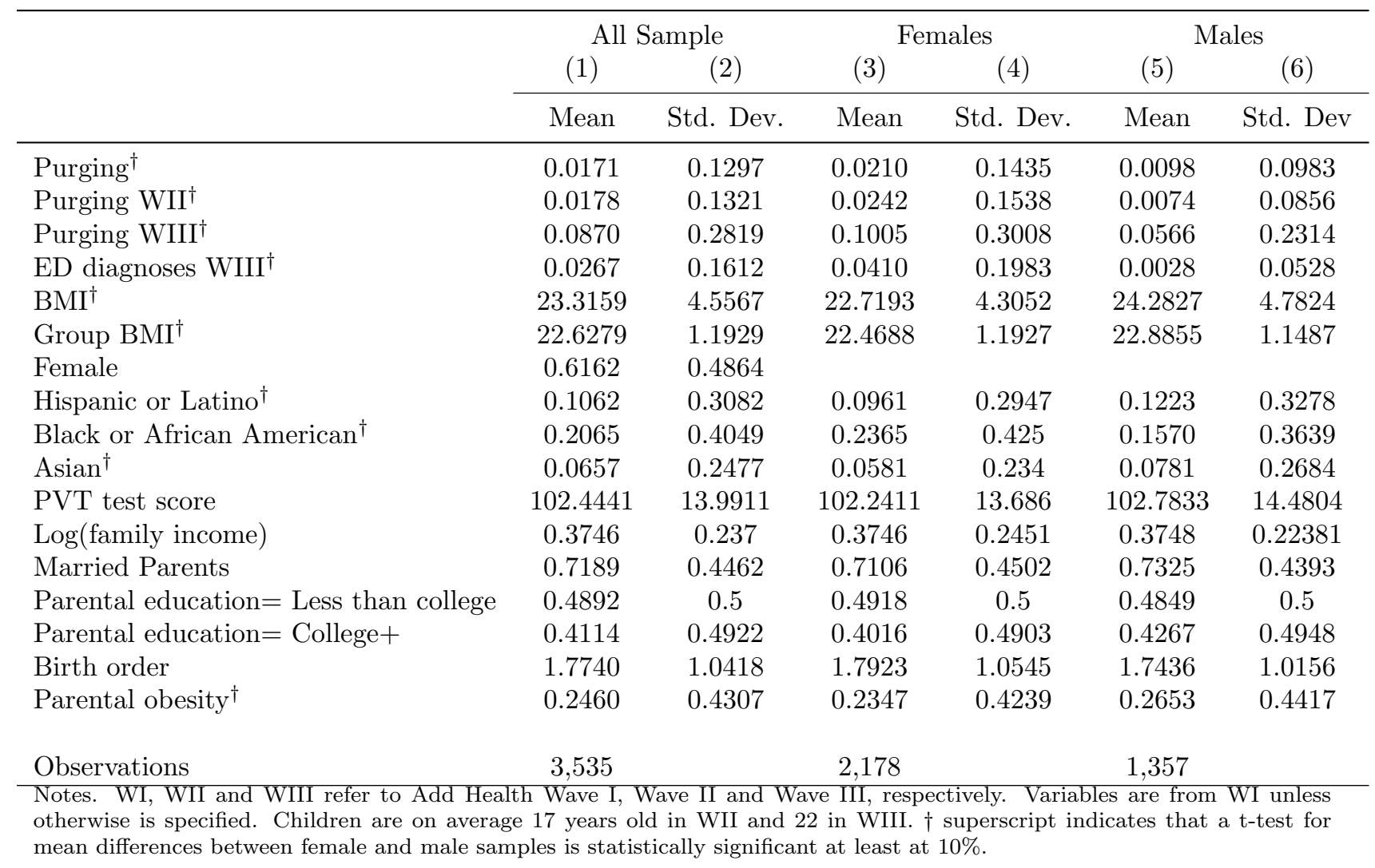


Table 2: Purging and Eating Disorders Diagnosis

\begin{tabular}{lccc}
\hline & $\begin{array}{c}(1) \\
\text { All Sample }\end{array}$ & $\begin{array}{c}(2) \\
\text { Females }\end{array}$ & $\begin{array}{c}(3) \\
\text { Males }\end{array}$ \\
\cline { 2 - 4 } & \multicolumn{3}{c}{ ED diagnosis WIII } \\
\hline \multirow{3}{*}{ Purging WII } & $0.0961^{*}$ & $0.1006^{*}$ & -0.0051 \\
Age WIII & $(0.0525)$ & $(0.0567)$ & $(0.0063)$ \\
& 0.0052 & 0.0050 & 0.0068 \\
Hispanic or Latino & $(0.0047)$ & $(0.0060)$ & $(0.0071)$ \\
Black or African American & $-0.0251^{* * *}$ & $-0.0375^{* * *}$ & -0.0101 \\
& $(0.0059)$ & $(0.0089)$ & $(0.0100)$ \\
Asian & $-0.0172^{* *}$ & $-0.0224^{* *}$ & -0.0084 \\
& $(0.0082)$ & $(0.0107)$ & $(0.0080)$ \\
Education level WIII & 0.0038 & 0.0189 & -0.0063 \\
\multirow{3}{*}{ Married WIII } & $(0.0197)$ & $(0.0352)$ & $(0.0059)$ \\
Log(Income) WIII & 0.0027 & 0.0042 & -0.0021 \\
Constant & $(0.0022)$ & $(0.0028)$ & $(0.0031)$ \\
& 0.0007 & -0.0034 & -0.0093 \\
Observations & $(0.0128)$ & $(0.0157)$ & $(0.0085)$ \\
& 0.0000 & 0.0000 & -0.0000 \\
& $(0.0000)$ & $(0.0000)$ & $(0.0000)$ \\
& -0.1343 & -0.1482 & -0.1124 \\
& $(0.1021)$ & $(0.1404)$ & $(0.1076)$ \\
& & & \\
& 1,624 & 1,121 & 500 \\
\hline
\end{tabular}

Notes. Controls variables are individual characteristics taken from Wave III, except race that is obtained from Wave I. Regressions are weighted using Add Health sample weights. ${ }^{*}: p<0.10$ * $^{* *}: p<0.05$; ***: $p<0.01$. 
Table 3: Variation in group BMI after removing school and grade fixed effects

\begin{tabular}{lcccc}
\hline \multicolumn{5}{c}{ Group BMI } \\
Panel (a) & mean & sd & $\min$ & $\max$ \\
& & & & \\
All sample & 22.6279 & 1.1929 & 18.4154 & 29.0814 \\
Females & 22.4688 & 1.1927 & 18.8900 & 26.7588 \\
Males & 22.8855 & 1.1487 & 18.4154 & 29.0814 \\
\multicolumn{5}{c}{} \\
& \multicolumn{5}{c}{} \\
& \multicolumn{5}{c}{ Residuals after removing } \\
School and grade fixed effects \\
Panel (b) & mean & sd & min & max \\
All sample & 0 & .9112 & -3.2600 & 5.7023 \\
Females & 0 & .7679 & -2.5112 & 2.8411 \\
Males & 0 & .7783 & -2.6590 & 7.1740 \\
\hline
\end{tabular}

Notes. The number of observations is 3,535 for the all sample, 2,178 for females and 1,357 for males. 
Table 4: Balancing Tests for group BMI

\begin{tabular}{|c|c|c|c|c|c|c|c|c|c|c|c|c|}
\hline Dep. Var: & $\begin{array}{l}\text { Parent } \\
\text { age }\end{array}$ & $\begin{array}{l}\text { Parent } \\
\text { born } \\
\text { in US }\end{array}$ & $\begin{array}{c}\text { Hispanic or } \\
\text { Latino }\end{array}$ & $\begin{array}{c}\text { Black } \\
\text { or African } \\
\text { American }\end{array}$ & Asian & $\begin{array}{l}\text { PVT } \\
\text { test } \\
\text { score }\end{array}$ & $\begin{array}{c}\text { Log } \\
\text { family } \\
\text { income }\end{array}$ & $\begin{array}{l}\text { Married } \\
\text { Parents }\end{array}$ & $\begin{array}{c}\text { Parental } \\
\text { education= } \\
\text { Less than } \\
\text { college }\end{array}$ & $\begin{array}{c}\text { Parental } \\
\text { education= } \\
\text { College }+\end{array}$ & $\begin{array}{l}\text { Birth } \\
\text { order }\end{array}$ & $\begin{array}{c}\text { Parental } \\
\text { obesity }\end{array}$ \\
\hline $\begin{array}{l}\text { All sample } \\
\text { Group BMI }\end{array}$ & $\begin{array}{l}-0.0174 \\
(0.1652)\end{array}$ & $\begin{array}{l}-0.0010 \\
(0.0060)\end{array}$ & $\begin{array}{l}0.0074^{*} \\
(0.0039)\end{array}$ & $\begin{array}{l}-0.0020 \\
(0.0060)\end{array}$ & $\begin{array}{l}-0.0045 \\
(0.0031)\end{array}$ & $\begin{array}{l}-0.2099 \\
(0.2700)\end{array}$ & $\begin{array}{c}-0.0090^{* *} \\
(0.0037)\end{array}$ & $\begin{array}{c}0.0007 \\
(0.0095)\end{array}$ & $\begin{array}{c}0.0091 \\
(0.0076)\end{array}$ & $\begin{array}{c}-0.0182^{*} \\
(0.0099)\end{array}$ & $\begin{array}{l}-0.0098 \\
(0.0225)\end{array}$ & $\begin{array}{l}-0.0095 \\
(0.0099)\end{array}$ \\
\hline $\begin{array}{l}\text { Females } \\
\text { Group BMI }\end{array}$ & $\begin{array}{l}-0.3483 \\
(0.2259)\end{array}$ & $\begin{array}{l}-0.0064 \\
(0.0073)\end{array}$ & $\begin{array}{c}0.0010 \\
(0.0048)\end{array}$ & $\begin{array}{c}0.0135 \\
(0.0092)\end{array}$ & $\begin{array}{c}-0.0058^{* *} \\
(0.0028)\end{array}$ & $\begin{array}{l}-0.3100 \\
(0.2901)\end{array}$ & $\begin{array}{l}-0.0059 \\
(0.0054)\end{array}$ & $\begin{array}{c}0.0253 \\
(0.0158)\end{array}$ & $\begin{array}{l}-0.0117 \\
(0.0074)\end{array}$ & $\begin{array}{l}-0.0030 \\
(0.0135)\end{array}$ & $\begin{array}{l}-0.0271 \\
(0.0297)\end{array}$ & $\begin{array}{c}0.0040 \\
(0.0098)\end{array}$ \\
\hline $\begin{array}{l}\text { Males } \\
\text { Group BMI }\end{array}$ & $\begin{array}{c}0.3455 \\
(0.3873)\end{array}$ & $\begin{array}{l}-0.0073 \\
(0.0111)\end{array}$ & $\begin{array}{c}0.0168^{* *} \\
(0.0079)\end{array}$ & $\begin{array}{l}-0.0048 \\
(0.0131)\end{array}$ & $\begin{array}{c}0.0056 \\
(0.0074)\end{array}$ & $\begin{array}{l}-0.4208 \\
(0.6018)\end{array}$ & $\begin{array}{c}-0.0214^{* * *} \\
(0.0080)\end{array}$ & $\begin{array}{l}-0.0034 \\
(0.0190)\end{array}$ & $\begin{array}{c}0.0160 \\
(0.0117)\end{array}$ & $\begin{array}{c}-0.0309 * \\
(0.0160)\end{array}$ & $\begin{array}{l}-0.0226 \\
(0.0293)\end{array}$ & $\begin{array}{l}-0.0276 \\
(0.0190)\end{array}$ \\
\hline $\begin{array}{l}\text { Fixed Effects } \\
\text { Grades }\end{array}$ & yes & yes & yes & yes & yes & yes & yes & yes & yes & yes & yes & yes \\
\hline Schools & yes & yes & yes & yes & yes & yes & yes & yes & yes & yes & yes & yes \\
\hline
\end{tabular}

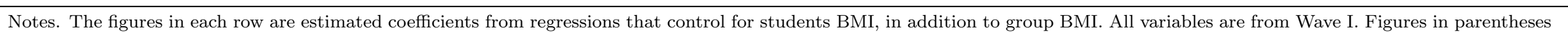
are standard errors robust to clustering at school-by-grade level. Regressions are weighted using Add Health sample weights. ${ }^{*}: p<0.10 ; * *: p<0.05 ; * * *: p<0.01$. 
Table 5: Main results- All sample

\begin{tabular}{|c|c|c|c|c|c|}
\hline Dep. Var.: Purging & (1) & $(2)$ & (3) & (4) & (5) \\
\hline Group BMI & $\begin{array}{c}-0.1662^{* *} \\
(0.0645)\end{array}$ & $\begin{array}{c}-0.1672^{* * *} \\
(0.0643)\end{array}$ & $\begin{array}{c}-0.1672^{* *} \\
(0.0654)\end{array}$ & $\begin{array}{c}-0.1670^{* *} \\
(0.0648)\end{array}$ & $\begin{array}{c}-0.1677^{* *} \\
(0.0654)\end{array}$ \\
\hline BMI & $\begin{array}{l}0.0481^{* *} \\
(0.0215)\end{array}$ & $\begin{array}{l}0.0506^{* *} \\
(0.0215)\end{array}$ & $\begin{array}{l}0.0505^{* *} \\
(0.0212)\end{array}$ & $\begin{array}{c}0.0496^{* *} \\
(0.0206)\end{array}$ & \\
\hline Female & $\begin{array}{c}0.0178^{* * *} \\
(0.0046)\end{array}$ & $\begin{array}{c}0.0179 * * * \\
(0.0047)\end{array}$ & $\begin{array}{c}0.0175^{* * *} \\
(0.0047)\end{array}$ & $\begin{array}{c}0.0174^{* * * *} \\
(0.0047)\end{array}$ & $\begin{array}{c}0.0141^{* * *} \\
(0.0043)\end{array}$ \\
\hline Hispanic or Latino & & $\begin{array}{c}-0.0112 \\
(0.0115)\end{array}$ & $\begin{array}{c}-0.0129 \\
(0.0121)\end{array}$ & $\begin{array}{c}-0.0128 \\
(0.0121)\end{array}$ & $\begin{array}{l}-0.0115 \\
(0.0119)\end{array}$ \\
\hline Black or African American & & $\begin{array}{l}-0.0165^{*} \\
(0.0097)\end{array}$ & $\begin{array}{c}-0.0211^{* *} \\
(0.0105)\end{array}$ & $\begin{array}{c}-0.0210^{* *} \\
(0.0105)\end{array}$ & $\begin{array}{l}-0.0168 \\
(0.0104)\end{array}$ \\
\hline Asian & & $\begin{array}{c}-0.0199^{* * *} \\
(0.0068)\end{array}$ & $\begin{array}{c}-0.0214^{* * *} \\
(0.0076)\end{array}$ & $\begin{array}{c}-0.0213^{* * *} \\
(0.0076)\end{array}$ & $\begin{array}{c}-0.0212^{* * *} \\
(0.0076)\end{array}$ \\
\hline PVT test score & & $\begin{array}{c}-0.0001 \\
(0.0002)\end{array}$ & $\begin{array}{l}-0.0000 \\
(0.0002)\end{array}$ & $\begin{array}{l}-0.0000 \\
(0.0002)\end{array}$ & $\begin{array}{l}-0.0000 \\
(0.0002)\end{array}$ \\
\hline $\log ($ family income) & & & $\begin{array}{l}-0.0112 \\
(0.0125)\end{array}$ & $\begin{array}{l}-0.0111 \\
(0.0122)\end{array}$ & $\begin{array}{l}-0.0106 \\
(0.0122)\end{array}$ \\
\hline Married Parents & & & $\begin{array}{c}-0.0143^{*} \\
(0.0085)\end{array}$ & $\begin{array}{c}-0.0143^{*} \\
(0.0085)\end{array}$ & $\begin{array}{c}-0.0141^{*} \\
(0.0086)\end{array}$ \\
\hline Parental education $=$ Less than college & & & $\begin{array}{c}0.0046 \\
(0.0103)\end{array}$ & $\begin{array}{c}0.0045 \\
(0.0103)\end{array}$ & $\begin{array}{c}0.0043 \\
(0.0102)\end{array}$ \\
\hline Parental education $=$ College + & & & $\begin{array}{c}0.0075 \\
(0.0119)\end{array}$ & $\begin{array}{c}0.0075 \\
(0.0118)\end{array}$ & $\begin{array}{c}0.0062 \\
(0.0118)\end{array}$ \\
\hline Birth order & & & $\begin{array}{c}0.0031 \\
(0.0026)\end{array}$ & $\begin{array}{c}0.0031 \\
(0.0026)\end{array}$ & $\begin{array}{c}0.0032 \\
(0.0026)\end{array}$ \\
\hline Parental obesity & & & & $\begin{array}{c}0.0012 \\
(0.0078)\end{array}$ & $\begin{array}{c}0.0073 \\
(0.0083)\end{array}$ \\
\hline Grade fixed effects & yes & yes & yes & yes & yes \\
\hline School fixed effects & yes & yes & yes & yes & yes \\
\hline Observations & 3,535 & 3,535 & 3,535 & 3,535 & 3,535 \\
\hline
\end{tabular}

Notes. Figures in parentheses are standard errors robust to clustering at the school-by-grade level. Regressions are weighted using Add Health sample weights. ${ }^{*}: p<0.10 ; * *: p<0.05 ;{ }^{* * *}: p<0.01$. 
Table 6: Within versus between gender targets

\begin{tabular}{|c|c|c|c|c|}
\hline \multirow[t]{2}{*}{ Dep. Var.: Purging } & (1) & $(2)$ & (3) & (4) \\
\hline & $\begin{array}{l}\text { Females } \\
\text { Females }\end{array}$ & $\begin{array}{l}\text { Males } \\
\text { Males }\end{array}$ & $\begin{array}{c}\text { Females } \\
\text { Males }\end{array}$ & $\begin{array}{c}\text { Males } \\
\text { Females }\end{array}$ \\
\hline Group BMI & $\begin{array}{c}-0.2047^{* *} \\
(0.0878)\end{array}$ & $\begin{array}{c}0.0384 \\
(0.0311)\end{array}$ & $\begin{array}{c}0.0359 \\
(0.0871)\end{array}$ & $\begin{array}{c}-0.0209 \\
(0.0490)\end{array}$ \\
\hline BMI & $\begin{array}{c}0.0792^{* *} \\
(0.0387)\end{array}$ & $\begin{array}{c}0.0242^{*} \\
(0.0125)\end{array}$ & $\begin{array}{c}0.0836^{* *} \\
(0.0394)\end{array}$ & $\begin{array}{l}0.0243^{*} \\
(0.0127)\end{array}$ \\
\hline Hispanic or Latino & $\begin{array}{c}-0.0069 \\
(0.0219)\end{array}$ & $\begin{array}{c}-0.0157 \\
(0.0105)\end{array}$ & $\begin{array}{c}-0.0070 \\
(0.0218)\end{array}$ & $\begin{array}{l}-0.0151 \\
(0.0105)\end{array}$ \\
\hline Black or African American & $\begin{array}{c}-0.0287^{*} \\
(0.0158)\end{array}$ & $\begin{array}{c}-0.0026 \\
(0.0028)\end{array}$ & $\begin{array}{c}-0.0295^{*} \\
(0.0157)\end{array}$ & $\begin{array}{l}-0.0026 \\
(0.0028)\end{array}$ \\
\hline Asian & $\begin{array}{c}-0.0345^{* * *} \\
(0.0109)\end{array}$ & $\begin{array}{c}-0.0076 \\
(0.0144)\end{array}$ & $\begin{array}{c}-0.0325^{* * *} \\
(0.0110)\end{array}$ & $\begin{array}{l}-0.0073 \\
(0.0143)\end{array}$ \\
\hline PVT test score & $\begin{array}{c}0.0000 \\
(0.0004)\end{array}$ & $\begin{array}{c}0.0001 \\
(0.0001)\end{array}$ & $\begin{array}{c}0.0000 \\
(0.0004)\end{array}$ & $\begin{array}{c}0.0001 \\
(0.0001)\end{array}$ \\
\hline Log(family income) & $\begin{array}{l}-0.0095 \\
(0.0187)\end{array}$ & $\begin{array}{c}-0.0069 \\
(0.0059)\end{array}$ & $\begin{array}{l}-0.0077 \\
(0.0187)\end{array}$ & $\begin{array}{l}-0.0075 \\
(0.0060)\end{array}$ \\
\hline Married Parents & $\begin{array}{c}-0.0247^{*} \\
(0.0138)\end{array}$ & $\begin{array}{c}0.0023 \\
(0.0048)\end{array}$ & $\begin{array}{c}-0.0260^{*} \\
(0.0139)\end{array}$ & $\begin{array}{c}0.0023 \\
(0.0049)\end{array}$ \\
\hline Parental education $=$ Less than college & $\begin{array}{c}0.0074 \\
(0.0164)\end{array}$ & $\begin{array}{c}-0.0063 \\
(0.0107)\end{array}$ & $\begin{array}{c}0.0066 \\
(0.0165)\end{array}$ & $\begin{array}{l}-0.0064 \\
(0.0109)\end{array}$ \\
\hline Parental education $=$ College + & $\begin{array}{c}0.0147 \\
(0.0191)\end{array}$ & $\begin{array}{c}-0.0084 \\
(0.0118)\end{array}$ & $\begin{array}{c}0.0141 \\
(0.0193)\end{array}$ & $\begin{array}{l}-0.0085 \\
(0.0120)\end{array}$ \\
\hline Birth order & $\begin{array}{c}0.0051 \\
(0.0043)\end{array}$ & $\begin{array}{c}0.0001 \\
(0.0012)\end{array}$ & $\begin{array}{c}0.0053 \\
(0.0043)\end{array}$ & $\begin{array}{c}0.0001 \\
(0.0013)\end{array}$ \\
\hline Parental obesity & $\begin{array}{c}0.0028 \\
(0.0127)\end{array}$ & $\begin{array}{c}0.0021 \\
(0.0051)\end{array}$ & $\begin{array}{c}0.0027 \\
(0.0127)\end{array}$ & $\begin{array}{c}0.0019 \\
(0.0051)\end{array}$ \\
\hline Grade fixed effects & yes & yes & yes & yes \\
\hline School fixed effects & yes & yes & yes & yes \\
\hline Observations & 2,178 & 1,357 & 2,178 & 1,357 \\
\hline
\end{tabular}

Notes. Figures in parentheses are standard errors robust to clustering at the school-by-grade level. Regressions are weighted using Add Health sample weights. ${ }^{*}: p<0.10{ }^{* *}: p<0.05 ;{ }^{* * *}: p<0.01$. 
Table 7: Relative BMI and body image distortion

\begin{tabular}{|c|c|c|c|c|}
\hline Dep. Var.: & $\begin{array}{c}(1) \\
\text { Purging }\end{array}$ & $\begin{array}{c}(2) \\
\text { Upward distortion }\end{array}$ & $\begin{array}{c}(3) \\
\text { Purging }\end{array}$ & $\begin{array}{c}(4) \\
\text { Purging }\end{array}$ \\
\hline Relative BMI & $\begin{array}{c}0.0881^{* *} \\
(0.0379)\end{array}$ & $\begin{array}{c}1.1540^{* * *} \\
(0.0929)\end{array}$ & & $\begin{array}{c}0.0432 \\
(0.0391)\end{array}$ \\
\hline $\begin{array}{l}\text { Relative BMI } \times \\
\text { Upward distortion }\end{array}$ & & & $\begin{array}{l}0.1850^{*} \\
(0.0954)\end{array}$ & \\
\hline $\begin{array}{l}\text { Relative BMI } \times \\
\text { Downward \& no distortion }\end{array}$ & & & $\begin{array}{l}-0.1642 \\
(0.0997)\end{array}$ & \\
\hline Upward distortion & & & $\begin{array}{c}0.0389 * * * \\
(0.0104)\end{array}$ & $\begin{array}{c}0.0354^{* * *} \\
(0.0101)\end{array}$ \\
\hline Hispanic or Latino & $\begin{array}{l}-0.0072 \\
(0.0219)\end{array}$ & $\begin{array}{c}0.0168 \\
(0.0618)\end{array}$ & $\begin{array}{l}-0.0035 \\
(0.0219)\end{array}$ & $\begin{array}{l}-0.0087 \\
(0.0212)\end{array}$ \\
\hline Black or African American & $\begin{array}{l}-0.0299^{*} \\
(0.0157)\end{array}$ & $\begin{array}{c}-0.1422^{* * *} \\
(0.0389)\end{array}$ & $\begin{array}{l}-0.0261^{*} \\
(0.0149)\end{array}$ & $\begin{array}{l}-0.0251 \\
(0.0153)\end{array}$ \\
\hline Asian & $\begin{array}{c}-0.0334^{* * *} \\
(0.0109)\end{array}$ & $\begin{array}{c}0.0195 \\
(0.0899)\end{array}$ & $\begin{array}{c}-0.0373^{* * *} \\
(0.0103)\end{array}$ & $\begin{array}{c}-0.0346^{* * *} \\
(0.0099)\end{array}$ \\
\hline PVT test score & $\begin{array}{c}0.0000 \\
(0.0004)\end{array}$ & $\begin{array}{l}0.0009 \\
(0.0011)\end{array}$ & $\begin{array}{c}0.0000 \\
(0.0004)\end{array}$ & $\begin{array}{c}0.0000 \\
(0.0004)\end{array}$ \\
\hline Log(family income) & $\begin{array}{l}-0.0086 \\
(0.0187)\end{array}$ & $\begin{array}{c}0.0422 \\
(0.0571)\end{array}$ & $\begin{array}{l}-0.0088 \\
(0.0185)\end{array}$ & $\begin{array}{l}-0.0103 \\
(0.0190)\end{array}$ \\
\hline Married Parents & $\begin{array}{l}-0.0254^{*} \\
(0.0138)\end{array}$ & $\begin{array}{l}-0.0256 \\
(0.0308)\end{array}$ & $\begin{array}{l}-0.0241^{*} \\
(0.0132)\end{array}$ & $\begin{array}{l}-0.0240^{*} \\
(0.0133)\end{array}$ \\
\hline Parental education $=$ Less than college & $\begin{array}{c}0.0070 \\
(0.0165)\end{array}$ & $\begin{array}{c}0.0595 \\
(0.0527)\end{array}$ & $\begin{array}{c}0.0065 \\
(0.0170)\end{array}$ & $\begin{array}{c}0.0049 \\
(0.0163)\end{array}$ \\
\hline Parental education $=$ College + & $\begin{array}{c}0.0144 \\
(0.0192)\end{array}$ & $\begin{array}{c}0.0731 \\
(0.0551)\end{array}$ & $\begin{array}{c}0.0109 \\
(0.0194)\end{array}$ & $\begin{array}{c}0.0118 \\
(0.0191)\end{array}$ \\
\hline Birth order & $\begin{array}{c}0.0052 \\
(0.0043)\end{array}$ & $\begin{array}{c}0.0047 \\
(0.0140)\end{array}$ & $\begin{array}{c}0.0047 \\
(0.0041)\end{array}$ & $\begin{array}{c}0.0050 \\
(0.0041)\end{array}$ \\
\hline Parental obesity & $\begin{array}{c}0.0019 \\
(0.0125)\end{array}$ & $\begin{array}{c}0.0384 \\
(0.0350)\end{array}$ & $\begin{array}{l}-0.0028 \\
(0.0115)\end{array}$ & $\begin{array}{c}0.0003 \\
(0.0120)\end{array}$ \\
\hline Grade fixed effects & yes & yes & yes & yes \\
\hline School fixed effects & yes & yes & yes & yes \\
\hline Observations & 2,178 & 2,178 & 2,178 & 2,178 \\
\hline
\end{tabular}

Notes. Figures in parentheses are standard errors robust to clustering at the school-by-grade level. Regressions are weighted using Add Health sample weights. ${ }^{*}: p<0.10 ; * *: p<0.05 ; * * *: p<0.01$. 
Table 8: Relative BMI and emotional distress

\begin{tabular}{|c|c|c|c|c|}
\hline Panel (a) & (1) & $(2)$ & $(3)$ & (4) \\
\hline Dep. Var.: & $\begin{array}{c}\text { Psychological } \\
\text { counseling }\end{array}$ & $\begin{array}{c}\text { Feel } \\
\text { depressed }\end{array}$ & $\begin{array}{l}\text { Doing } \\
\text { right }\end{array}$ & $\begin{array}{l}\text { Socially } \\
\text { accepted }\end{array}$ \\
\hline Relative BMI & $\begin{array}{c}0.1518^{* * *} \\
(0.0522)\end{array}$ & $\begin{array}{l}0.2759^{*} \\
(0.1490)\end{array}$ & $\begin{array}{c}-0.4227^{* * *} \\
(0.1528)\end{array}$ & $\begin{array}{c}-0.5150^{* * *} \\
(0.1392)\end{array}$ \\
\hline Panel (b) & (1) & $(2)$ & (3) & (4) \\
\hline \multicolumn{5}{|l|}{ Dep. Var.: Purging } \\
\hline Relative BMI & $\begin{array}{l}0.0790^{* *} \\
(0.0371)\end{array}$ & $\begin{array}{c}0.0785^{* *} \\
(0.0369)\end{array}$ & $\begin{array}{r}0.0795^{* *} \\
(0.0364)\end{array}$ & $\begin{array}{c}0.0795^{* *} \\
(0.0359)\end{array}$ \\
\hline Psychological counseling & $\begin{array}{l}0.0331^{*} \\
(0.0188)\end{array}$ & & & \\
\hline Feel depressed & & $\begin{array}{c}0.0199 * * * \\
(0.0066)\end{array}$ & & \\
\hline Feel doing right & & & $\begin{array}{l}-0.0107^{*} \\
(0.0059)\end{array}$ & \\
\hline Feel socially accepted & & & & $\begin{array}{l}-0.0085 \\
(0.0075)\end{array}$ \\
\hline Controls & yes & yes & yes & yes \\
\hline Grade fixed effects & yes & yes & yes & yes \\
\hline School fixed effects & yes & yes & yes & yes \\
\hline Observations & 2,177 & 2,177 & 2,172 & 2,172 \\
\hline
\end{tabular}

Notes. The control variables are listed in column 4 of Table 5 . Their estimated coefficients are shown in Tables B. 3 and B.4 of the online appendix. Figures in parentheses are standard errors robust to clustering at the school-by-grade level. Regressions are weighted using Add Health sample weights. ${ }^{*}: p<0.10{ }^{* *}: p<0.05 ;{ }^{* *}: p<0.01$. 
Table 9: Heterogeneous effects by individual attributes

\begin{tabular}{|c|c|c|c|c|c|}
\hline \multirow[t]{3}{*}{ Dep. Var.: Purging } & (1) & $(2)$ & $(3)$ & (4) & $(5)$ \\
\hline & \multicolumn{5}{|c|}{ Individual Attribute (X) } \\
\hline & BMI & Popularity & $\begin{array}{l}\text { Pvt } \\
\text { score }\end{array}$ & $\begin{array}{l}\text { Family } \\
\text { income }\end{array}$ & $\begin{array}{c}\text { Parental } \\
\text { education }\end{array}$ \\
\hline \multicolumn{6}{|l|}{ Group BMI × } \\
\hline \multirow{2}{*}{$X$ below group average } & -0.0196 & $-0.568^{*}$ & $-0.379^{*}$ & -0.189 & $-0.569 * *$ \\
\hline & $(0.125)$ & $(0.322)$ & $(0.194)$ & $(0.121)$ & $(0.227)$ \\
\hline \multirow[t]{2}{*}{$X$ around group average } & -0.1209 & -0.1570 & -0.1252 & $-0.2722^{* *}$ & -0.1127 \\
\hline & $(0.093)$ & $(0.103)$ & $(0.093)$ & $(0.106)$ & $(0.115)$ \\
\hline \multirow{2}{*}{$X$ above group average } & $-0.685^{* *}$ & -0.110 & -0.307 & 0.0722 & -0.105 \\
\hline & $(0.321)$ & $(0.110)$ & $(0.219)$ & $(0.148)$ & $(0.149)$ \\
\hline \multirow[t]{2}{*}{ BMI } & 0.0341 & $0.0799^{*}$ & $0.0743^{*}$ & $0.0772^{* *}$ & $0.0773^{* *}$ \\
\hline & $(0.042)$ & $(0.047)$ & $(0.038)$ & $(0.038)$ & $(0.038)$ \\
\hline \multirow{3}{*}{$\begin{array}{l}\text { Controls } \\
\text { Grade fixed effects } \\
\text { School fixed effects }\end{array}$} & yes & yes & yes & yes & yes \\
\hline & yes & yes & yes & yes & yes \\
\hline & yes & yes & yes & yes & yes \\
\hline Observations & 2,178 & 1,395 & 2,178 & 2,178 & 2,178 \\
\hline \multicolumn{6}{|c|}{$\begin{array}{l}\text { Notes. Let } \bar{X} \text { denote the average of attribute } X \text { in the reference group. " } X \text { below the group average" } \\
\text { is a dummy variable equal to } 1 \text { if } X<\bar{X}-1 \mathrm{sd} \text {, and } 0 \text { otherwise. "X around group average" is a } \\
\text { dummy variable equal to } 1 \text { if } X \in[\bar{X}-1 \mathrm{sd}, \bar{X}+1 \mathrm{sd}] \text {, and } 0 \text { otherwise. "X above group average" is } \\
\text { a dummy variable equal to } 1 \text { if } X>\bar{X}+1 \text { sd, and } 0 \text { otherwise. The table reports the estimates of the } \\
\text { parameters in model (3). The control variables are listed in column (4) of Table } 5 \text {. Their estimated } \\
\text { coefficients are shown in the Table B.2 of the online appendix. Figures in parentheses are standard } \\
\text { errors robust to clustering at the school-by-grade level. Regressions are weighted using Add Health } \\
\text { sample weights. *: } p<0.10 ; * *: p<0.05 ;{ }^{* *}: p<0.01 \text {. }\end{array}$} \\
\hline
\end{tabular}


Table 10: Nonlinear effects and alternative measures of reference points

Dep var.: Purging

$(1)$

$(2)$

$(3)$

(4)

\begin{tabular}{|c|c|c|c|c|}
\hline BMI & $\begin{array}{c}0.0792^{* *} \\
(0.0387)\end{array}$ & $\begin{array}{c}0.0809 * * \\
(0.0387)\end{array}$ & $\begin{array}{c}0.0832^{* *} \\
(0.0393)\end{array}$ & $\begin{array}{c}0.0826^{* *} \\
(0.0393)\end{array}$ \\
\hline Group BMI & $\begin{array}{c}-0.2047^{* *} \\
(0.0878)\end{array}$ & & & \\
\hline Group BMI in 2nd tercile & & $\begin{array}{c}-0.0234^{* *} \\
(0.0112)\end{array}$ & & \\
\hline Group BMI in 3rd tercile & & $\begin{array}{c}-0.0303^{* *} \\
(0.0123)\end{array}$ & & \\
\hline Proportion of UW & & & $\begin{array}{c}0.1001^{* * *} \\
(0.0378)\end{array}$ & \\
\hline Proportion of UW in 2nd tercile & & & & $\begin{array}{c}0.0133 \\
(0.0098)\end{array}$ \\
\hline Proportion of UW in 3rd tercile & & & & $\begin{array}{l}0.0158^{*} \\
(0.0084)\end{array}$ \\
\hline Hispanic or Latino & $\begin{array}{c}-0.0069 \\
(0.0219)\end{array}$ & $\begin{array}{c}-0.0070 \\
(0.0221)\end{array}$ & $\begin{array}{c}-0.0079 \\
(0.0219)\end{array}$ & $\begin{array}{c}-0.0069 \\
(0.0219)\end{array}$ \\
\hline Black or African American & $\begin{array}{c}-0.0287^{*} \\
(0.0158)\end{array}$ & $\begin{array}{c}-0.0289^{*} \\
(0.0159)\end{array}$ & $\begin{array}{c}-0.0298^{*} \\
(0.0158)\end{array}$ & $\begin{array}{c}-0.0296^{*} \\
(0.0158)\end{array}$ \\
\hline Asian & $\begin{array}{c}-0.0345^{* * *} \\
(0.0109)\end{array}$ & $\begin{array}{c}-0.0355^{* * *} \\
(0.0111)\end{array}$ & $\begin{array}{c}-0.0308^{* * *} \\
(0.0114)\end{array}$ & $\begin{array}{c}-0.0320^{* * *} \\
(0.0110)\end{array}$ \\
\hline PVT test score & $\begin{array}{c}0.0000 \\
(0.0004)\end{array}$ & $\begin{array}{c}0.0000 \\
(0.0004)\end{array}$ & $\begin{array}{c}0.0000 \\
(0.0004)\end{array}$ & $\begin{array}{c}0.0000 \\
(0.0004)\end{array}$ \\
\hline Log(family income) & $\begin{array}{l}-0.0095 \\
(0.0187)\end{array}$ & $\begin{array}{c}-0.0103 \\
(0.0183)\end{array}$ & $\begin{array}{c}-0.0076 \\
(0.0187)\end{array}$ & $\begin{array}{l}-0.0080 \\
(0.0187)\end{array}$ \\
\hline Married Parents & $\begin{array}{c}-0.0247^{*} \\
(0.0138)\end{array}$ & $\begin{array}{c}-0.0248^{*} \\
(0.0139)\end{array}$ & $\begin{array}{c}-0.0260^{*} \\
(0.0138)\end{array}$ & $\begin{array}{l}-0.0263^{*} \\
(0.0139)\end{array}$ \\
\hline Parental education $=$ Less than college & $\begin{array}{c}0.0074 \\
(0.0164)\end{array}$ & $\begin{array}{c}0.0077 \\
(0.0165)\end{array}$ & $\begin{array}{c}0.0065 \\
(0.0165)\end{array}$ & $\begin{array}{c}0.0068 \\
(0.0165)\end{array}$ \\
\hline Parental education $=$ College + & $\begin{array}{c}0.0147 \\
(0.0191)\end{array}$ & $\begin{array}{c}0.0155 \\
(0.0193)\end{array}$ & $\begin{array}{c}0.0139 \\
(0.0193)\end{array}$ & $\begin{array}{c}0.0144 \\
(0.0192)\end{array}$ \\
\hline Birth order & $\begin{array}{c}0.0051 \\
(0.0043)\end{array}$ & $\begin{array}{c}0.0049 \\
(0.0042)\end{array}$ & $\begin{array}{c}0.0052 \\
(0.0042)\end{array}$ & $\begin{array}{c}0.0052 \\
(0.0043)\end{array}$ \\
\hline Parental obesity & $\begin{array}{c}0.0028 \\
(0.0127)\end{array}$ & $\begin{array}{c}0.0029 \\
(0.0127)\end{array}$ & $\begin{array}{c}0.0027 \\
(0.0127)\end{array}$ & $\begin{array}{c}0.0026 \\
(0.0127)\end{array}$ \\
\hline Grade fixed effects & yes & yes & yes & yes \\
\hline School fixed effects & yes & yes & yes & yes \\
\hline Observations & 2,178 & 2,178 & 2,178 & 2,178 \\
\hline
\end{tabular}

Notes. "Group BMI in 2nd tercile" is a dummy variable equal to 1 if the group BMI belongs to the $\in$ [33th percentile, 66th percentile] interval of the group BMI distribution, and 0 otherwise. "Group BMI in 3rd tercile" is a dummy variable equal to 1 if the group BMI is above the 66th percentile, and 0 otherwise. "Proportion of UW in 2nd" and "Proportion of UW in 3rd tercile" follow the corresponding definition. Figures in parentheses are standard errors robust to clustering at the school-by-grade level. Regressions are weighted using Add Health sample weights. ${ }^{*}: p<0.10 ; * *: p<0.05 ;{ }^{* * *}: p<0.01$. 


\section{Appendix A: Additional Figures and Tables}

Figure A.1: Individual BMI and group BMI distributions

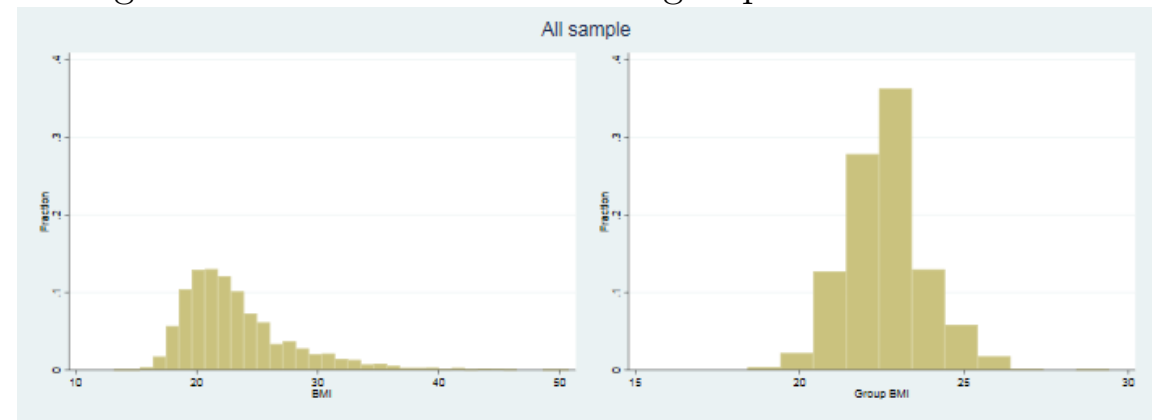

Figure A.2: Distribution of group BMI by group size

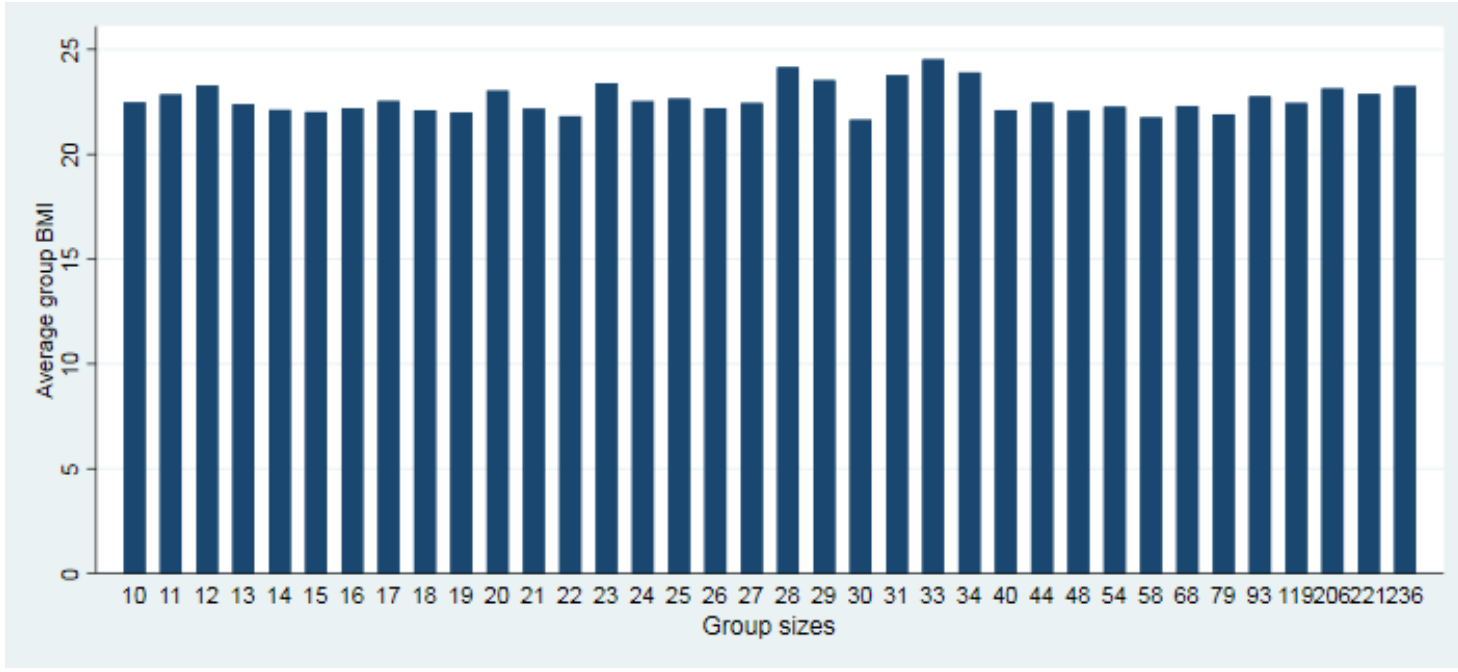


Figure A.3: Distribution of $\theta_{2}$ for placebo estimates

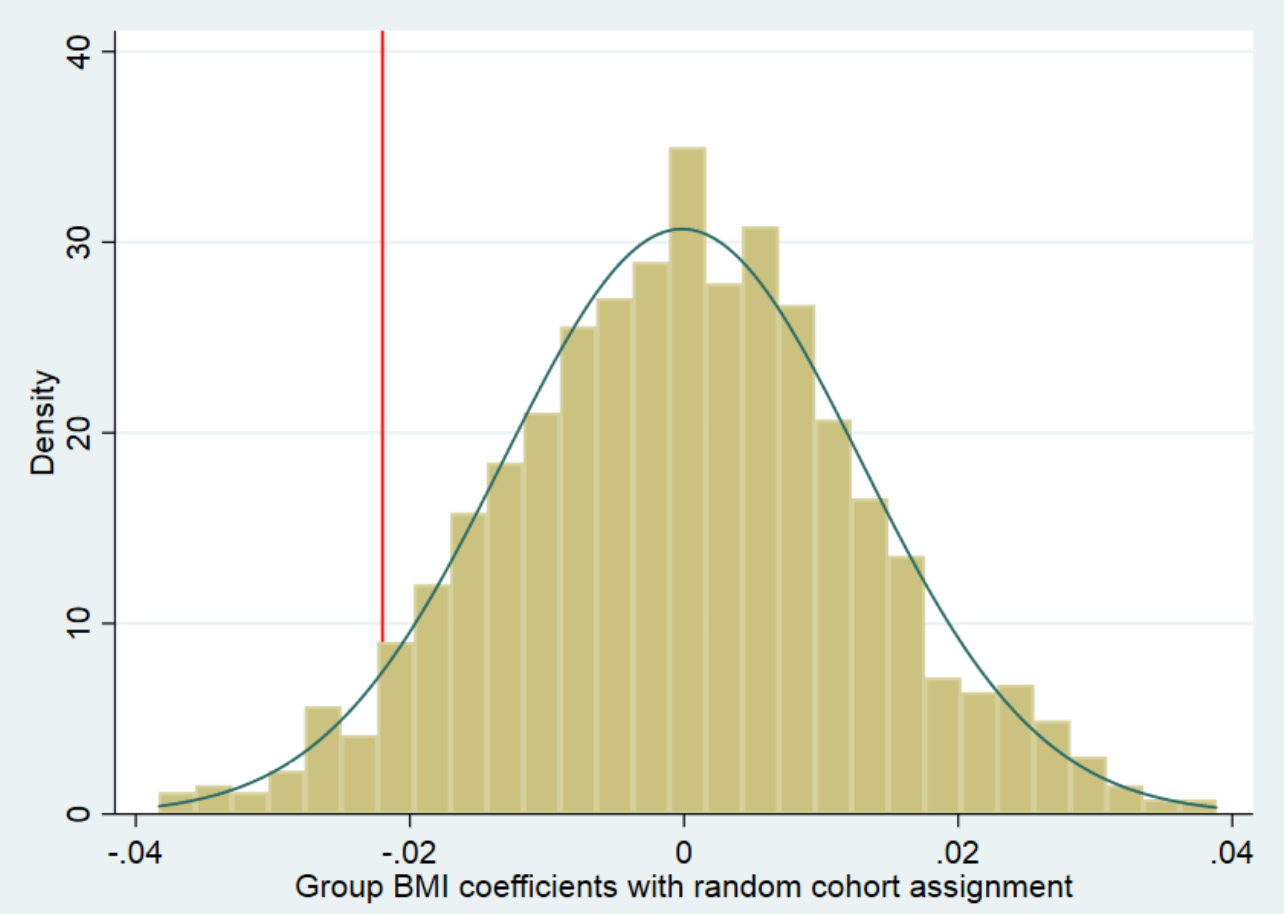

Notes. For each student, we replace the actual cohort BMI with that one of a randomly selected cohort from the same school. We run 1,000 of these placebo regressions. The vertical line is the value of $\theta_{2}$ in model (1) reported in the benchmark regression in Table 6 (column (1)) for females. 
Table A.1: Sample selection procedure

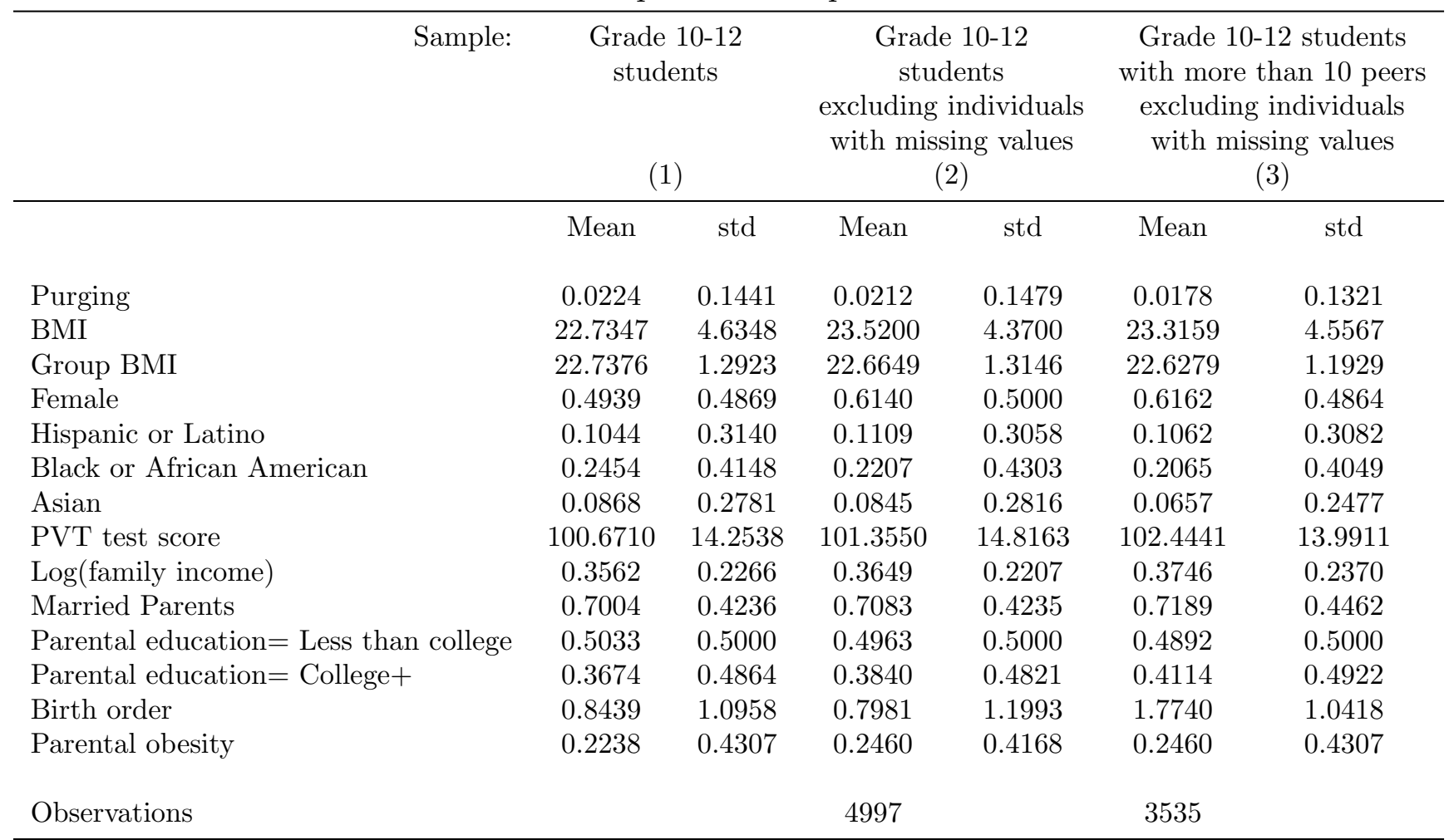

Notes. The table reports descriptive statistics for the main variables used in the analysis at each stage of the sample selection process. Column (1) reports information on the original sample of respondents in grades 10-12. Note that for each row the sample size is different in column (1) because each variable has a different number of non-missing values. In the second column we exclude students with missing information on at least one of the variables listed in the table, including those reporting an unclear racial background. In the last column, we exclude students who have less than 10 schoolmates in the same grade. This is our final sample selection. 
Table A.2: Robustness checks: peers' family background

Dep. Var.: Purging

(1)

(2)

(3)

Group BMI

BMI

Fraction of peers with married parents

Fraction of peers with Parental education= Less than college

Fraction of peers with Parental education $=$ College +

Fraction of peers with parents obese

Hispanic or Latino

Black or African American

Asian

PVT test score

$\log ($ family income)

Married parents

Parental education $=$ Less than college

Parental education $=$ College +

Birth order

Parental obesity

Grade fixed effects

School fixed effects

\begin{tabular}{|c|c|c|}
\hline$-0.2110^{* *}$ & $-0.1897^{* *}$ & $-0.2004^{* *}$ \\
\hline$(0.0871)$ & $(0.0886)$ & $(0.0851)$ \\
\hline $0.0787^{* *}$ & $0.0795^{* *}$ & $0.0794^{* *}$ \\
\hline$(0.0386)$ & $(0.0387)$ & $(0.0387)$ \\
\hline \multicolumn{3}{|l|}{$\begin{array}{l}-0.0416 \\
(0.0421)\end{array}$} \\
\hline \multirow{4}{*}{\multicolumn{3}{|c|}{$(0.0421)$}} \\
\hline & & \\
\hline & & \\
\hline & & \\
\hline & & $\begin{array}{l}-0.0133 \\
(0.0353)\end{array}$ \\
\hline-0.0063 & -0.0060 & -0.0069 \\
\hline$(0.0219)$ & $(0.0219)$ & $(0.0219)$ \\
\hline$-0.0284^{*}$ & $-0.0278^{*}$ & $-0.0289^{*}$ \\
\hline$(0.0158)$ & $(0.0157)$ & $(0.0158)$ \\
\hline$-0.0346^{* * *}$ & $-0.0320^{* * *}$ & $-0.0346^{* * *}$ \\
\hline$(0.0108)$ & $(0.0111)$ & $(0.0109)$ \\
\hline 0.0000 & 0.0000 & -0.0000 \\
\hline$(0.0004)$ & $(0.0004)$ & $(0.0004)$ \\
\hline-0.0097 & -0.0077 & -0.0094 \\
\hline$(0.0188)$ & $(0.0187)$ & $(0.0187)$ \\
\hline$-0.0254^{*}$ & $-0.0253^{*}$ & $-0.0249^{*}$ \\
\hline$(0.0136)$ & $(0.0139)$ & $(0.0139)$ \\
\hline 0.0071 & 0.0043 & 0.0075 \\
\hline$(0.0165)$ & $(0.0163)$ & $(0.0164)$ \\
\hline 0.0141 & 0.0091 & 0.0149 \\
\hline (0.0194) & $(0.0187)$ & $(0.0193)$ \\
\hline 0.0049 & 0.0050 & 0.0051 \\
\hline$(0.0042)$ & $(0.0043)$ & $(0.0043)$ \\
\hline 0.0027 & 0.0030 & 0.0024 \\
\hline$(0.0127)$ & $(0.0127)$ & $(0.0124)$ \\
\hline yes & yes & yes \\
\hline yes & yes & yes \\
\hline 2,178 & 2,178 & 2,178 \\
\hline
\end{tabular}

Notes. Figures in parentheses are standard errors robust to clustering at the school-by-grade level. Regressions are weighted using Add Health sample weights. ${ }^{*}: p<0.10$; $^{*}: p<0.05 ;{ }^{* *}: p<0.01$. 
Table A.3: Robustness checks: additional individual and peers' characteristics

\begin{tabular}{|c|c|c|c|c|c|c|c|c|c|c|}
\hline Dep. Var.: Purging & (1) & $(2)$ & $(3)$ & $(4)$ & $(5)$ & (6) & $(7)$ & $(8)$ & (9) & (10) \\
\hline Additional characteristic $(\mathrm{X})$ : & $\begin{array}{l}\text { Alcohol } \\
\text { at home }\end{array}$ & $\begin{array}{l}\text { Family } \\
\text { counseling }\end{array}$ & $\begin{array}{l}\text { Mother } \\
\text { relationship } \\
\text { satisfaction }\end{array}$ & $\begin{array}{l}\text { Parents } \\
\text { care }\end{array}$ & $\begin{array}{l}\text { Dinner } \\
\text { with } \\
\text { parents }\end{array}$ & $\begin{array}{c}\text { Infant } \\
\text { breastfeeding }\end{array}$ & $\begin{array}{c}\text { Sport } \\
\text { activity }\end{array}$ & $\begin{array}{l}\text { Junk } \\
\text { food }\end{array}$ & $\begin{array}{l}\text { individuals } \\
\text { alcohol } \\
\text { consumption }\end{array}$ & $\begin{array}{c}\text { Building } \\
\text { quality }\end{array}$ \\
\hline Group BMI & $\begin{array}{c}-0.2056^{* *} \\
(0.0890)\end{array}$ & $\begin{array}{c}-0.1825^{* *} \\
(0.0873)\end{array}$ & $\begin{array}{c}-0.2165^{* *} \\
(0.0895)\end{array}$ & $\begin{array}{c}-0.2188^{* *} \\
(0.0876)\end{array}$ & $\begin{array}{c}-0.2097^{* *} \\
(0.0859)\end{array}$ & $\begin{array}{c}-0.2346^{* *} \\
(0.0934)\end{array}$ & $\begin{array}{c}-0.1957^{* *} \\
(0.0845)\end{array}$ & $\begin{array}{c}-0.2011^{* *} \\
(0.0885)\end{array}$ & $\begin{array}{c}-0.2125^{* *} \\
(0.0883)\end{array}$ & $\begin{array}{r}-0.2019^{* *} \\
(0.0874)\end{array}$ \\
\hline BMI & $\begin{array}{c}0.0792^{* *} \\
(0.0397)\end{array}$ & $\begin{array}{c}0.0807 * * \\
(0.0386)\end{array}$ & $\begin{array}{l}0.0750^{*} \\
(0.0397)\end{array}$ & $\begin{array}{l}0.0745^{*} \\
(0.0381)\end{array}$ & $\begin{array}{c}0.0852^{* *} \\
(0.0390)\end{array}$ & $\begin{array}{c}0.0791^{* *} \\
(0.0392)\end{array}$ & $\begin{array}{c}0.0788^{* *} \\
(0.0383)\end{array}$ & $\begin{array}{l}0.0740 * \\
(0.0390)\end{array}$ & $\begin{array}{c}0.0837^{* *} \\
(0.0381)\end{array}$ & $\begin{array}{c}0.0776 * * \\
(0.0381)\end{array}$ \\
\hline $\mathrm{X}$ & $\begin{array}{l}-0.0009 \\
(0.0040)\end{array}$ & $\begin{array}{l}0.0529^{*} \\
(0.0289)\end{array}$ & $\begin{array}{c}-0.0128^{* *} \\
(0.0049)\end{array}$ & $\begin{array}{c}-0.0323^{* * *} \\
(0.0116)\end{array}$ & $\begin{array}{c}-0.0066^{* * *} \\
(0.0021)\end{array}$ & $\begin{array}{c}0.0098 \\
(0.0105)\end{array}$ & $\begin{array}{l}-0.0294 \\
(0.0247)\end{array}$ & $\begin{array}{c}-0.0105^{* *} \\
(0.0050)\end{array}$ & $\begin{array}{c}0.0105^{* *} \\
(0.0052)\end{array}$ & $\begin{array}{c}0.0062 \\
(0.0064)\end{array}$ \\
\hline Controls & yes & yes & yes & yes & yes & yes & yes & yes & yes & yes \\
\hline Group controls & yes & yes & yes & yes & yes & yes & yes & yes & yes & yes \\
\hline Grade fixed effects & yes & yes & yes & yes & yes & yes & yes & yes & yes & yes \\
\hline School fixed effects & yes & yes & yes & yes & yes & yes & yes & yes & yes & yes \\
\hline Observations & 2,147 & 2,177 & 2,115 & 2,173 & 2,174 & 2,136 & 2,178 & 2,178 & 2,173 & 2,162 \\
\hline
\end{tabular}

Notes. Each regression also includes the additional characteristic at the peer level. Namely, $(\bar{X})$ is the average of variable $X$ in the reference group. The estimated

coefficients are shown in Table B.1 of the online appendix. The set Controls is listed in column (4) of Table 5. The estimated coefficients are shown in Table B.1 of the online appendix. Figures in parentheses are standard errors robust to clustering at the school-by-grade level. Regressions are weighted using Add Health sample weights. * $: p<0.10 ;{ }^{* *}: p<0.05$; $^{* *}: p<0.01$. 
Table A.4: Robustness checks: saturated sample

\begin{tabular}{|c|c|c|c|c|}
\hline Dep. Var.: Purging & (1) & $(2)$ & (3) & (4) \\
\hline Group BMI & $\begin{array}{c}-0.5646^{* * * *} \\
(0.1947)\end{array}$ & $\begin{array}{c}-0.5556^{* * * *} \\
(0.1870)\end{array}$ & $\begin{array}{c}-0.5815^{* * * *} \\
(0.1837)\end{array}$ & $\begin{array}{c}-0.5863^{* * *} \\
(0.1828)\end{array}$ \\
\hline BMI & $\begin{array}{c}0.0499 \\
(0.0612)\end{array}$ & $\begin{array}{c}0.0467 \\
(0.0568)\end{array}$ & $\begin{array}{c}0.0474 \\
(0.0551)\end{array}$ & $\begin{array}{c}0.0534 \\
(0.0532)\end{array}$ \\
\hline Hispanic or Latino & & $\begin{array}{c}0.0035 \\
(0.0233)\end{array}$ & $\begin{array}{c}0.0045 \\
(0.0256)\end{array}$ & $\begin{array}{c}0.0030 \\
(0.0260)\end{array}$ \\
\hline Black or African American & & $\begin{array}{c}0.0132 \\
(0.0182)\end{array}$ & $\begin{array}{c}0.0039 \\
(0.0201)\end{array}$ & $\begin{array}{c}0.0013 \\
(0.0210)\end{array}$ \\
\hline Asian & & $\begin{array}{c}-0.0535^{* * *} \\
(0.0097)\end{array}$ & $\begin{array}{c}-0.0490^{* *} \\
(0.0228)\end{array}$ & $\begin{array}{c}-0.0497^{* *} \\
(0.0236)\end{array}$ \\
\hline PVT test score & & $\begin{array}{c}0.0003 \\
(0.0007)\end{array}$ & $\begin{array}{c}0.0002 \\
(0.0007)\end{array}$ & $\begin{array}{c}0.0002 \\
(0.0008)\end{array}$ \\
\hline Log(family income) & & & $\begin{array}{c}-0.0108 \\
(0.0361)\end{array}$ & $\begin{array}{l}-0.0113 \\
(0.0361)\end{array}$ \\
\hline Married Parents & & & $\begin{array}{l}-0.0259 \\
(0.0297)\end{array}$ & $\begin{array}{c}-0.0258 \\
(0.0295)\end{array}$ \\
\hline Parental education $=$ Less than college & & & $\begin{array}{c}0.0416 \\
(0.0271)\end{array}$ & $\begin{array}{c}0.0428 \\
(0.0281)\end{array}$ \\
\hline Parental education $=$ College + & & & $\begin{array}{c}0.0200 \\
(0.0218)\end{array}$ & $\begin{array}{c}0.0218 \\
(0.0232)\end{array}$ \\
\hline Birth order & & & $\begin{array}{c}0.0042 \\
(0.0034)\end{array}$ & $\begin{array}{c}0.0039 \\
(0.0033)\end{array}$ \\
\hline Parental obesity & & & & $\begin{array}{l}-0.0088 \\
(0.0109)\end{array}$ \\
\hline Grade fixed effects & yes & yes & yes & yes \\
\hline School fixed effects & yes & yes & yes & yes \\
\hline Observations & 565 & 565 & 565 & 565 \\
\hline
\end{tabular}

Notes. Add health in-home saturated sample is used in all columns. Figures in parentheses are standard errors robust to clustering at the school-by-grade level. Regressions are weighted using Add Health sample weights. ${ }^{*}: p<0.10 ; * *: p<0.05 ; * *: p<0.01$. 
Table A.5: OLS vs Logit

\begin{tabular}{|c|c|c|}
\hline Dep. Var.: Purging & $\begin{array}{c}\text { (1) } \\
\text { Conditional Logit }\end{array}$ & $\begin{array}{l}(2) \\
\text { OLS }\end{array}$ \\
\hline Group BMI & $\begin{array}{c}-9.0310^{* *} \\
(4.2553)\end{array}$ & $\begin{array}{c}-0.5895^{* *} \\
(0.2580)\end{array}$ \\
\hline BMI & $\begin{array}{c}2.2529^{* * *} \\
(0.8292)\end{array}$ & $\begin{array}{c}0.1579^{* *} \\
(0.0738)\end{array}$ \\
\hline Female & & \\
\hline Hispanic or Latino & $\begin{array}{l}-0.3360 \\
(0.5712)\end{array}$ & $\begin{array}{l}-0.0199 \\
(0.0458)\end{array}$ \\
\hline Black or African American & $\begin{array}{c}-1.2302^{* *} \\
(0.5505)\end{array}$ & $\begin{array}{l}-0.0748^{*} \\
(0.0425)\end{array}$ \\
\hline Asian & $\begin{array}{c}-1.2430 * * * \\
(0.3691)\end{array}$ & $\begin{array}{c}-0.0783^{* * *} \\
(0.0282)\end{array}$ \\
\hline PVT test score & $\begin{array}{l}-0.0061 \\
(0.0111)\end{array}$ & $\begin{array}{l}-0.0002 \\
(0.0010)\end{array}$ \\
\hline $\log$ (family income) & $\begin{array}{l}-0.4685 \\
(0.4616)\end{array}$ & $\begin{array}{l}-0.0210 \\
(0.0293)\end{array}$ \\
\hline Married Parents & $\begin{array}{l}-0.0880 \\
(0.4903)\end{array}$ & $\begin{array}{l}-0.0555^{*} \\
(0.0302)\end{array}$ \\
\hline Parental education $=$ Less than college & $\begin{array}{c}0.2019 \\
(0.3618)\end{array}$ & $\begin{array}{c}0.0091 \\
(0.0345)\end{array}$ \\
\hline Parental education $=$ College + & $\begin{array}{c}0.2816 \\
(0.3864)\end{array}$ & $\begin{array}{c}0.0283 \\
(0.0412)\end{array}$ \\
\hline Birth order & $\begin{array}{c}0.0803 \\
(0.1433)\end{array}$ & $\begin{array}{c}0.0137 \\
(0.0115)\end{array}$ \\
\hline Parental obesity & $\begin{array}{l}-0.2924 \\
(0.3496)\end{array}$ & $\begin{array}{c}0.0004 \\
(0.0301)\end{array}$ \\
\hline Grade fixed effects & yes & yes \\
\hline School fixed effects & yes & yes \\
\hline Observations & 1,054 & 1,054 \\
\hline
\end{tabular}

Notes. Figures in parentheses are standard errors robust to clustering at the school-bygrade level. Regressions are weighted using Add Health sample weights. ${ }^{*}: p<0.10 ;{ }^{* *}$ : $p<0.05 ; * * *: p<0.01$. 